\title{
Deciphering the calcitriol-induced transcriptomic response in keratinocytes: presentation of novel target genes
}

\author{
Raphaela Rid*, Martin Wagner*, Christina J Maier, Harald Hundsberger', \\ Helmut Hintner, Johann W Bauer and Kamil Önder
}

Division of Molecular Dermatology, Department of Dermatology, Paracelsus Private Medical University Salzburg, Müllner Haupstraße 48, 5020 Salzburg, Austria ${ }^{1}$ Department of Medical and Pharmaceutical Biotechnology, University of Applied Sciences, 3500 Krems, Austria

*(R Rid and M Wagner contributed equally to this work.)
Correspondence should be addressed to K Onder Email k.oender@salk.at

\begin{abstract}
Numerous studies to date have been aimed at unraveling the large suite of calcitriol $(1 \alpha, 25-$ dihydroxyvitamin $D_{3}$ ) response genes in diverse tissues including skin, where this hormone is involved in regulating keratinocyte proliferation, differentiation, permeability barrier formation, innate immunity promotion, antimicrobial peptide production, and wound healing. However, the various approaches differ considerably in probed cell types, scale, throughput, and statistical reliability and do, of note, not reveal much overlap. To further expand our knowledge on presently elusive targets and characterize the extent of fragmentation of existing datasets, we have performed whole-transcriptome microarray examinations of calcitriol-treated human primary keratinocytes. Out of 28869 genes investigated, we uncovered 86 differentially expressed (67 upregulated and 19 downregulated) candidates that were functionally clustered into five annotation categories: response to wounding, protease inhibition, secondary metabolite biosynthesis, cellular migration, and amine biosynthetic processes. A complementary RTq-PCR study of 78 nominees selected thereof demonstrated significant differential expression of 55 genes (48 upregulated and seven downregulated) within biological replicates. Our hit list contains nine previously authenticated targets $(16.36 \%$, proof of concept) and 46 novel genes $(83.6 \%)$ that have not yet been explicitly described as being differentially regulated within human primary keratinocytes. Direct vitamin $D$ receptor response element predictions within the regulatory promoter regions of 50 of the RTq-PCR-validated targets agreed with known biological functionality and corroborated our stringent data validation pipeline. Altogether, our results indicate the value of continuing these kinds of gene expression studies, which contribute to an enhanced comprehension of calcitriol-mediated processes that may be dysregulated in human skin pathophysiology.
\end{abstract}

\section{Key Words}

- calcitriol signaling

- calcitriol response genes

- primary keratinocytes

- gene expression profiling
Journal of Molecular Endocrinology

(2013) 50, 131-149 http://jme.endocrinology-journals.org DOI: 10.1530/JME-11-0191
() 2013 Society for Endocrinology Printed in Great Britain
Published by Bioscientifica Ltd 


\section{Introduction}

Metazoan epidermis consists of four distinguishable layers containing primarily keratinocytes at distinct stages of development (Bikle et al. 2007, Poumay \& Coquette 2007). Following their initial proliferation in the epidermal bottom stratum basale, the majority of daughters undergo a process of (terminal) differentiation accompanied by characteristic morphological alterations as well as changes in biochemical markers as they continuously migrate upward to the outmost cornified, enucleated stratum corneum skin surface (Lu et al. 2005, Carlberg \& Seuter 2007, Bikle 2010). A central regulator of keratinocyte (and also of other normal vs malignant cell types) growth and differentiation is hereby calcitriol (1 $\alpha, 25$-dihydroxyvitamin $D_{3}$ ) (McLane et al. 1990, Svendsen et al. 1997, Cianferotti et al. 2007), classically recognized for its role in $\mathrm{Ca}^{++}$equilibrium maintenance essential for bone integrity. Calcitriol not only differentially affects expression of certain epidermal differentiation markers (Su et al. 1994, Lutzow-Holm et al. 1995, Bikle et al. 2002, Xie et al. 2002) but also governs permeability barrier formation (Oda et al. 2009). It protects keratinocytes from apoptosis (Lee \& Youn 1998, Diker-Cohen et al. 2003) and has gained attention for its role in innate immune defense (Wang et al. 2004, Schauber et al. 2007). Remarkably, keratinocytes comprise the only cell population that possesses the entire metabolic equipment for autonomous synthesis of calcitriol from the 7-dehydrocholesterol precursor both in vitro (Lehmann et al. 2001) and in vivo (Lehmann et al. 2003). Thus, skin represents both the sites of production of calcitriol and is also the target organ for this potent, hormonally active secosteroid (Ebert et al. 2006, Norman 2006, Reichrath et al. 2007, Schmuth et al. 2007). Genomic control of primary calcitriol response genes is hereby achieved by attachment of ligand-bound vitamin $\mathrm{D}$ receptor (VDR)/retinoid $\mathrm{X}$ receptor (RXR) heterodimers to vitamin $\mathrm{D}$ response elements (VDREs) located within respective promoter regions (Rastinejad et al. 1995, Shaffer \& Gewirth 2002, Carlberg 2003, Carlberg $\&$ Seuter 2007). Binding of calcitriol to VDR triggers the release of corepressor proteins (Polly et al. 2000, Carlberg 2004, Privalsky 2004, Carlberg \& Seuter 2007, Reichrath et al. 2007) through a conformational change within the VDR ligand-binding domain. A subsequent recruitment of coactivators collectively mediates local chromatin remodeling and builds a stable bridge to the basal transcriptional machinery (Hermanson et al. 2002, Eelen et al. 2006, Carlberg \& Seuter 2007). In addition, calcitriol can also mediate 'rapid responses' that are elicited by putative receptor(s) located near or associated with the plasma membrane and its caveolae compartments (Boyan et al. 2006). These effects occur within minutes after hormone administration, which precludes a mechanism involving changes in gene expression, but appears instead to direct an increase in second messengers that can, ultimately, affect transcription through cross talk with other signal transduction cascades (Wali et al. 1990, Losel \& Wehling 2003). Evidently, calcitriol target gene activation constitutes a multistep process, permitting keratinocytes to finely adjust their physiological responses to calcitriol (Darimont et al. 1998, Rosenfeld \& Glass 2001).

The last few years have witnessed the introduction of global oligonucleotide and cDNA microarrays as increasingly appreciated, powerful instruments to reproducibly examine drug- and disease-induced steady-state snapshots of the (differential) expression of thousands of targets in massively parallel fashion (Kawasaki 2006, Auer et al. 2009). Together, with complementary chromatin immunoprecipitation (ChIP and sophisticated modifications developed thereof, such as genome-wide ChIPchip hybridization of resultant chromatin fragments on microarrays or massively parallel ChIP-seq sequencings) and in silico screens for VDREs, they have largely rationalized the entirety of nuclear hormone receptor superfamily research (Tavera-Mendoza et al. 2006, Carlberg \& Seuter 2009, Carlberg \& Heinäniemi 2010, Meyer et al. 2010, Pike et al. 2010), which previously relied on the transfection of 'indirect' reporter gene chimeras (Lemon \& Freedman 1996). To date, in-depth deciphering of calcitriol-triggered transcriptional changes has been achieved in both primary cells and established (tumor) cell lines derived from multiple tissues. Each of these studies has resulted in the uncovering of a far from exhaustive, barely overlapping list of (merely moderate- to high-ranking quality) response genes implicated in diverse biological processes. Only two studies have actually been devoted to either immortalized (Lu et al. 2005) or primary human keratinocytes (Moll et al. 2007). In our endeavor to further expand our knowledge on calcitriol target genes, we have applied a global whole-transcriptome microarray to delineate alterations within hormone-induced transcriptomic changes and have confirmed the results with complementary RTq-PCR and in silico promoter scanning. In doing so, we have been able to verify nine candidates previously described as differentially regulated in human keratinocytes to connect more than 30 additional targets reported from diverse other (tumor) tissue-derived lines

Published by Bioscientifica Ltd. 
with primary keratinocyte functioning and to define 13 potentially new, likely keratinocyte-specific genes. A graphical overview of our experimental design and outcomes is shown in Fig. 1.

\section{Materials and methods}

\section{Cultivation of primary keratinocytes from human foreskin tissue}

Clinically normal (uninflamed, sunlight-protected) human foreskin tissue obtained after informed consent from six individuals aged between 4 and 12 years in the course of routine surgery (phimosis, religious ritual; Children's Hospital, SALK/PMU, Salzburg, Austria) was incubated for $2 \mathrm{~min}$ in $100 \%$ ethanol to eliminate any bacterial contamination, neutralized in Dulbecco's PBS (Sigma-Aldrich), aseptically sliced into small pieces, and incubated at $4{ }^{\circ} \mathrm{C}$ overnight in Dispase solution
(2.24 units, GIBCO brand, Invitrogen $\mathrm{GmbH}$ ) diluted 1:1 in buffer A (30 mM HEPES, $10 \mathrm{mM}$ glucose, $3 \mathrm{mM} \mathrm{KCl}$, $130 \mathrm{mM} \mathrm{NaCl}$, and $1 \mathrm{mM} \mathrm{Na} \mathrm{HPO}_{4}, 1 \times$ phenol red, $\mathrm{pH} 7.4$ ) to gently disaggregate the epidermis from the underlying dermis. As described previously (Bikle et al. 1986, Trost et al. 2010), primary keratinocytes were harvested from separated foreskin epidermis via incubation with repeated vigorous shaking for $15 \mathrm{~min}$ in trypsin-EDTA (PAA Laboratories $\mathrm{GmbH}$, Pasching, Austria) diluted $1: 10$ in buffer $\mathrm{A}$ at $37^{\circ} \mathrm{C}$. The resultant epidermal cell suspension was neutralized with fetal bovine serum (PAA Laboratories, 1:10 in buffer A) and centrifuged for $5 \mathrm{~min}$ at $206 \boldsymbol{g}$ (Varifuge 3.0 RS, Heraeus Instruments, Hanau, Germany). The cell pellet was then resuspended in $5 \mathrm{ml}$ defined serum-free SFM medium (kit) containing L-glutamine, EGF ( $5 \mu \mathrm{g} / \mathrm{l})$, and bovine pituitary extract $(50 \mathrm{mg} / \mathrm{l})$ and a calcium chloride concentration of $0.09 \mathrm{mM}$ (Gibco, Invitrogen $\mathrm{GmbH}$ ) and filtered through a $40 \mu \mathrm{m}$ cell strainer (BD Biosciences, Heidelberg,

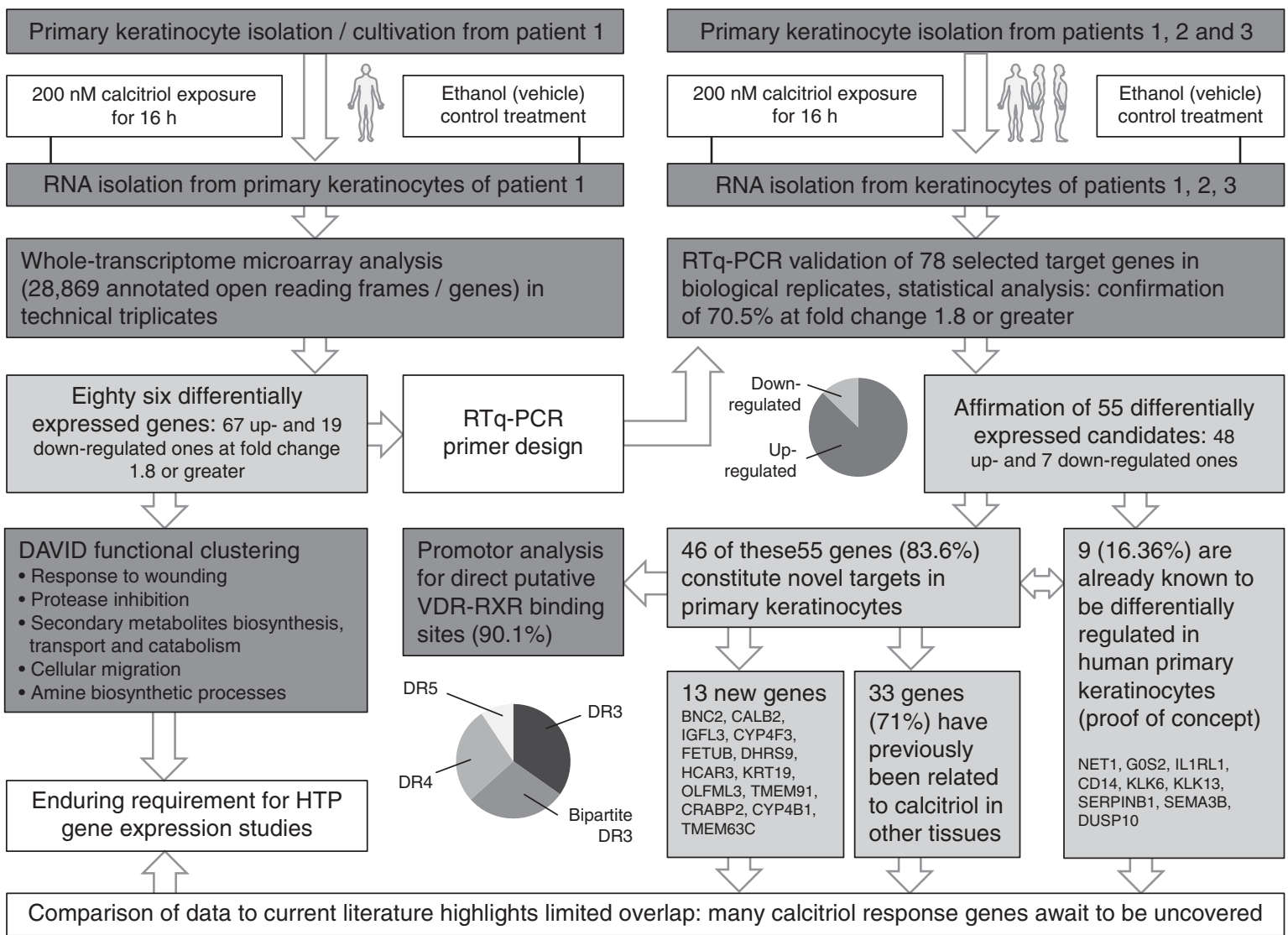

Figure 1

Schematic illustration of our experimental strategy (plus resultant data) applied for the identification of differentially expressed calcitriol targets within primary human keratinocytes.

http://jme.endocrinology-journals.org DOI: 10.1530/JME-11-0191
() 2013 Society for Endocrinology Printed in Great Britain
Published by Bioscientifica Ltd 
Germany). Cells in suspension were centrifuged again, seeded in $75 \mathrm{~cm}^{2}$ flasks (TPP, Trasadingen, Switzerland), and incubated in SFM medium at $37^{\circ} \mathrm{C}, 5 \% \mathrm{CO}_{2}$. Cells were subsequently passaged until passage three ( $\sim 3$ weeks) in keratinocyte-specific SFM medium formulated to inhibit fibroblast growth. For calcitriol exposure, the hormone (Sigma-Aldrich) was solubilized in $100 \%$ ethanol, diluted to the desired concentration in culture medium, and administered to the cells, growing at a confluency of about 70-80\%, at a final concentration of supraphysiological $200 \mathrm{nM}$ for $16 \mathrm{~h}$ (individuals 1,2 , and 3: microarray, RTq-PCR) vs more physiological $1 \mathrm{nM}$ for $8 \mathrm{~h}$ (individuals 4, 5, and 6: RTq-PCR). Mock controls (ethanol vehicle) were analogously treated.

\section{RNA isolation from cultivated primary keratinocytes}

Total RNA from cells grown to $\sim 80 \%$ confluence was extracted with an RNeasy Midi Kit (Qiagen $\mathrm{GmbH}$ ) according to the manufacturer's instructions, resuspended in DEPC-treated nuclease-free water, and quantified spectrophotometrically (Ultraspec 2000, Amersham Pharmacia) at $260 \mathrm{~nm}$ (Oender et al. 2008). Resultant preparations were appraised as being suitable for subsequent DNA microarray hybridization only if samples were of sufficient yield, exhibited intact bands corresponding to the $18 S$ and $28 S$ rRNA subunits as determined by agarose gel electrophoresis in formaldehyde-supplemented $1 \times$ MOPS running buffer, and simultaneously displayed no spurious peaks or RNA degradation artifacts on the u.v. absorption spectrum. Portions of the total RNA samples were stored (long term) at $-80^{\circ} \mathrm{C}$.

\section{Whole-transcript Affymetrix microarray assessment}

Technical triplicate aliquots of total RNA per treatment condition were forwarded to the Kompetenzzentrum Fluoreszente Bioanalytik (KFB, Regensburg, Germany) for use in probing a high-precision, whole-transcript Human Gene 1.0 ST array (Affymetrix, Santa Clara, CA, USA). The entire experimental pipeline from sense target labeling to hybridization, washing, array scanning, and final raw data capture was performed as part of a comprehensive, commercial solution including standard Affymetrix protocols, reagents, and instrumentation meeting-certified performance criteria. Returned raw data were checked for quality, background-adjusted, and quantile-normalized and analyzed by the linear model for microarray data (LIMMA) statistical method. Normalized $\log 2$ intensity values were rank-ordered; fold-changes in gene expression were calculated; and $P$ values, a statistical measure of consistency between paired groups, were determined using Student's $t$-test.

\section{Functional clustering of differentially expressed genes}

To more thoroughly characterize the resultant set of genes, we employed the bioinformatics resource DAVID version 6.7 (http://david.abcc.ncifcrf.gov/) to annotate candidates according to their involvement in diverse (redundant) cellular processes, pathways, or components by controlled vocabulary gene ontology (GO) assignment (Ashburner et al. 2000). DAVID (Sherman et al. 2007, Huang da et al. 2009) permits systematic identification of biological themes significantly accumulated within particular (differentially expressed) gene collections at nominal $P<0.05$ with the transcript population comprising the Affymetrix Human Gene 1.0 ST arrays as background. Explicit categorization was achieved using a modified Fisher exact probability test, in the course of which the significance $(P)$ for each assembled group was calculated as the negative log-transformed enrichment score (ES; Hosack et al. 2003).

\section{Confirmatory RTq-PCR}

RefSeq accession IDs of differentially expressed genes were subjected to Batch Entrez analysis (http://www.ncbi.nlm. nih.gov/sites/batchentrez) for exposing mRNA sequences. These were forwarded to the WIBR UTR extractor (http:// jura.wi.mit.edu/bioc/tools/utrs) to excerpt coding regions and pasted into the Primer 3 program (http://frodo.wi.mit. edu/primer) to generate automatically designed (and manually controlled) oligonucleotides with similar properties (uniform GC content/melting temperature, optimal length, and similar amplicon size) to guarantee accurate results. Forward and reverse primer stocks $(100 \mathrm{pmol} / \mu \mathrm{l})$ were purchased in 96-well format from Invitrogen $\mathrm{GmbH}$. After a 20-min digestion of total human RNA preparations from three different individuals with DNase I (deoxyribonuclease kit, Sigma-Aldrich) at room temperature, $1.5 \mu \mathrm{g}$ pure RNA was reverse transcribed into cDNA using an iScript cDNA synthesis kit (Bio-Rad Laboratories) according to the supplier's instructions. Resultant cDNA served as the template for subsequent RTq-PCR in plate format using a GoTaq qPCR Master Mix (Promega Corporation, Madison, WI, USA) plus a CFX96 apparatus (Bio-Rad, Hercules, CA, USA). Each run profiled the expression of differentially expressed genes in relation to seven unregulated housekeeping transcripts (B2M, HPRT1,

Published by Bioscientifica Ltd. 
RPL13A, GAPDH, ACTB, ANXA1, and TUBB) serving as internal references for data normalization, determination of experimental variance, and optimal fold-change cutoff estimation. Two built-in intron-specific probes for KRT14 intron 1 and BEST1 intron 2 were used for assessing possible contamination with genomic DNA. All reactions were carried out in a final volume of $25 \mu \mathrm{l}$. Product quality was checked by post-PCR melting curve analysis. Fold inductions were calculated according to a mathematical model described by Pfaffl (2001) employing the formula $2^{-(\Delta \Delta C \mathrm{t})}$ (where $\Delta \Delta C \mathrm{t}$ is $\Delta C \mathrm{t}_{\text {calcitriol }}$ minus $\Delta C \mathrm{t}_{\text {ethanol, }} \Delta C \mathrm{t}$ designates $C \mathrm{t}_{\text {sample }}-C \mathrm{t}_{\text {housekeeping-pool, }}$ and $C \mathrm{t}$ denotes the cycle at which the threshold is crossed). A fold-change cutoff of 1.8 was implemented to record the final list of statistically ascertained (homoscedastic $t$-test, $P<0.05$ ) differentially expressed calcitriol target genes in human primary keratinocytes.

\section{In silico screening for (putative) VDR response elements}

Genomic sequences of differentially expressed genes located within a distance of approximately -3000 to +150 bps from their respective transcription start site (TSS) were directly inferred from Genomatix 's annotated ElDorado (version 08-2011, built on NCBI build 37)/ Gene2Promoter database or manually downloaded from Cold Spring Harbor Laboratory's mammalian promoter database (version 05-2005, NCBI build 35) (Xuan et al. 2005). Promoter regions were interactively screened in both orientations for (predicted) theoretical nuclear hormone receptor superfamily transcription factor (VDR-RXR heterodimer)-binding sites using optimized, fixed similarity thresholds via MatInspector 8.0 (Genomatix, Ann Arbor, MI, USA) with its embedded weighted nucleotide distribution matrix family concept (library version 8.4, 06-2011) (Cartharius et al. 2005). 'Core similarity' is herein defined as the maximally conserved positions. 'Matrix similarity' (perfect match: score of 1.00, acceptable match: $>0.80$ ) additionally takes into account all bases over the entire matrix distance, with mismatches in conserved positions decreasing the score more than discrepancies in less conserved domains.

\section{Exemplary electrophoretic mobility agarose gel shift assay}

The promoter fragments (100-200 bp) harboring central MatInspector predicted (bipartite) DR3-type VDREs for CRABP2 (forward: 5'-CAAGCCCCTCTCTGAGTACG-3', reverse: 5'-GATGCTCAGGGCTCGTGTAT-3'), OLFML3
(5' -TCCCAGTGGTAAGGAAGTCAG-3', $5^{\prime}$-TTGCTTGAAAGAGGCCAGAT-3'), BNC2 (5'-GTCAAGCATGCCTGTGAAGA-3', 5'-GGCCCTCCTTATTTCAGTCC-3'), TMEM91 (5'-CCACGATCACTTCACTGCAC-3', 5'-GCCTTAACCAAGGACCTTCC-3'), and KRT19 (5'-CTGCTGTGAGGATCCAGTGA-3', 5'-GTCTGGGGAGGGACTTTGTA-3') were PCR amplified from genomic DNA isolated from cultured human keratinocytes (Gentra Puregene, Qiagen $\mathrm{GmbH}$ ) with the Primer3-designed oligonucleotides listed in brackets. The VDR DNA-binding domain (DBD, AA 16-125) (Sone et al. 1991) was shuttled into recombinational cloning compatible destination vector pDEST 17 (Life Technologies), transformed into Escherichia coli BL21 (DE3) cells, expressed via $1 \mathrm{mM}$ isopropyl $\beta$-D-1-thiogalactopyranoside (IPTG) induction, and then purified as recombinant hexahistidine-tagged fusion protein by nickel affinity chromatography following common procedures. To investigate binding of VDR-DBD to amplified promoters, $600 \mathrm{ng}$ of respective PCR products were incubated with recombinant DBD in $100 \mathrm{mM}$ Tris buffer in a total reaction volume of $20 \mu \mathrm{l}$ for $5 \mathrm{~min}$ and subsequently separated on a 1\% agarose gel in $1 \times \mathrm{TAE}$ buffer. Samples were visualized for apparent electrophoretic mobility shifts in relation to a previously described osteopontin DR3 repeat (Hijiya et al. 1994) positive control (5'-CGCAGAGCATTTGCATCTAA-3', $5^{\prime}$-GGTTCTGAATTCCGCTGTGT-3') plus four analogously treated negative control DNA fragments (designated as C7, D1, A12 and G8) containing no definite VDRE. Band intensities were densitometrically quantified via ImageJ software (http://rsbweb.nih.gov/ij/docs/index.html).

\section{Results}

\section{Global transcriptional profiling uncovers known and novel calcitriol response genes in human primary keratinocytes}

To develop a comprehensive picture of calcitriol-mediated changes in gene expression patterns, total RNA isolated from proliferating primary keratinocytes treated with $200 \mathrm{nM}$ calcitriol for $16 \mathrm{~h}$ was subjected to a commercially available microarray hybridization service (Dalma-Weiszhausz et al. 2006). Before definite sample submission, an aliquot of RNA was pretested in a miniature scale RTq-PCR analysis to ensure that a calcitriol response could be detected at the level of mRNA induction as judged by an increase in CYP24A1 expression (Anderson et al. 2003) (data not shown). The interrogated Affymetrix human 1.0 ST gene chip platform offers coverage of roughly the entire

Published by Bioscientifica Ltd. 
transcriptome wherein each of the 28869 annotated constituents is cumulatively represented by $\sim 26$ distinct perfect match-only designed probes spread across the entire length of the genes (including 20000 generic background/hybridization controls), resulting in high intra-platform consistency, robustness, and reproducibility (Shi et al. 2006, Sarmah \& Samarasinghe 2011). A preliminary, unbiased, preprocessed, normalized raw data summary identified 86 probe sets as differentially expressed (67 upregulated and 19 downregulated genes with fold changes of 1.8 or greater) under calcitriol exposure compared with reference conditions. For subsequent RTq-PCR validation, this list was reduced to a cohort of 78 promising candidate calcitriol response genes, employing only those genes whose pattern of expression was consistent in all three independently performed technical replicates and across all probe sets that detect the same gene.

\section{Functional clustering suggests enrichment of genes involved in response to wounding, secondary metabolite biosynthesis, protease inhibition, cellular migration, and amine biosynthetic processes}

We next assigned biological themes to our authenticated, calcitriol-modulated genes by taking advantage of the web-accessible DAVID knowledgebase, an integrated highthroughput data mining environment (Sherman et al. 2007, Huang da et al. 2009). Employing pre-adjusted 'medium' default parameter settings, five annotation categories appeared to be significantly enriched among our identified cohort of 78 genes. These clusters encompass response to wounding/inflammatory response (ES 2.58), protease inhibition (ES 2.01), secondary metabolite biosynthesis, transport, and catabolism (ES 2.2), cellular migration (ES 1.44), and amine biosynthetic processes (ES1.33).

\section{The majority of microarray-identified targets can be reproduced in RTq-PCR analysis using biological replicate samples}

Differential expression patterns of the candidate $200 \mathrm{nM} / 16 \mathrm{~h}$ calcitriol response genes in primary human keratinocytes isolated from three different individuals was separately assessed by RTq-PCR analysis. The RTq-PCR analysis permits identification of induction or repression as relative fold changes in transcript levels compared with seven internal unregulated reference housekeeping gene transcripts (Walker 2001, Dallas et al. 2005, Provenzano \&
Mocellin 2007). RTq-PCR data from all three individuals were integrated, and 55 candidates were definitively authenticated. We found that 48 of these were congruently upregulated (Fig. 2) and seven were downregulated (Fig. 3). Although mean interindividual variation, the percentaged relative s.D. across individuals in the calcitriol-stimulated vs ethanol-treated control group, was experimentally determined to be $\sim 10 \%$ (Table 1 ), which would encourage selection of a fold change cutoff of 1.1, we chose a more stringent selection. Only genes with a fold change of at least 1.8 and $P<0.05$ were considered to be explicit 'hits'. As highlighted in Figs 2 and 3, mean fold changes over three biological and technical replicates in all tested cases autonomously verified our earlier findings. Additionally, we performed RTq-PCR analyses on primary keratinocytes isolated from another set of three individuals, which were stimulated with a physiological dose of $1 \mathrm{nM}$ calcitriol for $8 \mathrm{~h}$ using the same 78 probe panel. As depicted in Figs 2 and 3, though the fold changes are not as high, all genes, except $A B H D 3$, are regulated in the same directions as upon stimulation with $200 \mathrm{nM}$ for $16 \mathrm{~h}$. However, with a fold change of at least 1.8, 23 genes were congruently upregulated and two were downregulated. Mean interindividual variation was again determined to be $\sim 10 \%$ (Table 1 ).

\section{Comparison of differentially regulated targets to current literature indicates the necessity for ongoing gene expression profiling studies}

Based on an in-depth literature survey (Pubmed database) of currently available expression profiling studies investigating differential calcitriol-mediated gene expression in diverse cell and tissue types, our final list of 55 candidate calcitriol-regulated genes includes 46 candidates whose responsiveness has, to the best of our knowledge, not been observed previously in human primary keratinocytes, and nine genes (NET1, GOS2, IL1RL1, CD14, KLK6, KLK13, SERPINB1, SEMA3B, and DUSP10) previously identified as calcitriol-regulated genes in human primary keratinocytes. In addition, as can be perceived from Fig. 1, 33 candidates have previously been related to calcitriol in diverse (tumor-derived) cell lines, and 13 candidates (BNC2, CALB2, IGFL3, CYP4F3, FETUB, DHRS9, HCAR3, KRT19, OLFML3, TMEM91, CRABP2, CYP4B1, and TMEM63C) have not previously been identified as being regulated by calcitriol. Because overlap between the various individual studies is limited, ongoing efforts will be necessary for fully elucidating all calcitriol response genes.

Published by Bioscientifica Ltd. 


\begin{tabular}{|c|c|c|c|c|c|}
\hline & & & \multirow{3}{*}{$\begin{array}{l}\text { MA } \\
\text { Fold }\end{array}$} & \multicolumn{2}{|c|}{ RTq-PCR } \\
\hline & & & & $200 \mathrm{nM} / 16 \mathrm{~h}$ & $1 \mathrm{nM} / 8 \mathrm{~h}$ \\
\hline GenBank & Symbol & Gene description & & Fold & Fold \\
\hline NM_005502 & $A B C A 1$ & ATP-binding cassette, sub family A (ABC1), member 1 & 2.7 & 4.3 & 1.7 \\
\hline NM_138340 & ABHD3 & Abhydrolase domain containing 3 & 2.0 & 1.8 & -2.5 \\
\hline NM_005100 & AKAP12 & A kinase (PRKA) anchor protein 12 & 2.3 & 8.8 & 1.7 \\
\hline NM_017637 & BNC2 & Basonuclin 2 & 1.9 & 4.6 & 1.5 \\
\hline NM_016289 & CAB39 & Calcium binding protein 39 & 1.9 & 3.2 & 1.5 \\
\hline NM_007088 & CALB2 & Calbindin 2 & 1.9 & 6.2 & 1.3 \\
\hline NM_000591 & CD14 & CD14 molecule & 11.2 & 218.7 & \\
\hline NM_014143 & CD274 & CD274 molecule & 3.1 & 3.1 & \\
\hline NM_001784 & CD97 & CD97 molecule & 2.1 & 4.2 & 1.9 \\
\hline NM_001785 & $C D A$ & Cytidine deaminase & 1.9 & 2.7 & 1.6 \\
\hline NM_018413 & CHST11 & Carbohydrate (chondroitin 4) sulfotransferase 11 & 2.0 & 3.6 & 1.5 \\
\hline NM_001307 & CLDN7 & Claudin 7 & 2.0 & 2.9 & 1.2 \\
\hline NM_024734 & CLMN & Calmin (calponin-like, transmembrane) & 2.6 & 2.5 & 1.9 \\
\hline NM_020361 & CPA6 & Carboxypeptidase A6 & 2.4 & ND & ND \\
\hline NM_000782 & CYP24A1 & Cytochrome P450, family 24, subfamily A, polypeptide 1 & 66.5 & ND & ND \\
\hline NM_000777 & CYP3A5 & Cytochrome P450, family 3, subfamily A, polypeptide 5 & 2.1 & 4.0 & 3.3 \\
\hline NM_021187 & CYP4F11 & Cytochrome P450, family 4, subfamily F, polypeptide 11 & 2.6 & - & 1.7 \\
\hline NM_000896 & CYP4F3 & Cytochrome P450, family 4, subfamily F, polypeptide 3 & 2.2 & 4.4 & 2.7 \\
\hline NM_005771 & DHRS9 & Dehydrogenase/reductase (SDR family) member 9 & 3.3 & 4.4 & 2.2 \\
\hline NM_007207 & DUSP10 & Dual specificity phosphatase 10 & 5.2 & 6.9 & 1.6 \\
\hline NM_024580 & EFTUD1 & Elongation factor Tu GTP binding domain containing 1 & 2.9 & 3.6 & 2.4 \\
\hline NM_018208 & ETNK2 & Ethanolamine kinase 2 & 2.5 & 4.0 & 1.8 \\
\hline NM_052966 & FAM129A & Family with sequence similarity 129, member $A$ & 1.9 & 2.1 & 1.7 \\
\hline NM_015714 & G0S2 & G0/G1switch 2 & 3.0 & 6.9 & 1.9 \\
\hline NM_000402 & G6PD & Glucose-6-phosphate dehydrogenase & 1.9 & - & 2.4 \\
\hline NM_019593 & GPCPD1 & Hypothetical protein KIAA1434 & 2.3 & 2.6 & \\
\hline NM_001945 & HBEGF & Heparin-binding EGF-like growth factor & 1.9 & - & 1.3 \\
\hline NM_177551 & HCAR2 & Hydroxycarboxylic acid receptor 2 & 2.3 & ND & ND \\
\hline NM_006018 & HCAR3 & Hydroxycarboxylic acid receptor 3 & 2.1 & 4.5 & 1.3 \\
\hline NM_002165 & ID1 & Inhibitor of DNA binding 1, dominant negative helix-loop-helix protein & 1.8 & 3.6 & 1.6 \\
\hline NM_207393 & IGFL3 & IGF-like family member 3 & 2.2 & 4.0 & 1.9 \\
\hline NM_000576 & IL1B & Interleukin $1, \beta$ & 2.1 & - & 1.2 \\
\hline NM_003856 & IL1RL1 & Interleukin 1 receptor-like 1 & 4.4 & 45.3 & \\
\hline NM_000216 & KAL1 & Kallmann syndrome 1 sequence & 1.8 & ND & ND \\
\hline NM_015990 & KLHL5 & Kelch-like 5 ( Drosophila) & 1.9 & 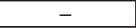 & 1.2 \\
\hline NM_015596 & KLK13 & Kallikrein-related peptidase 13 & 2.8 & 10.7 & 2.3 \\
\hline NM_002774 & KLK6 & Kallikrein-related peptidase 6 & 9.2 & 21.6 & 23.3 \\
\hline NM_002276 & KRT19 & Keratin 19 & 2.0 & 3.4 & 1.6 \\
\hline NM_001031749 & LYPD5 & LY6/PLAUR domain containing 5 & 2.4 & - & 1.8 \\
\hline NM_173803 & MPV17L & MPV17 mitochondrial membrane protein-like & 1.9 & - & \\
\hline NM_000433 & NCF2 & Neutrophil cytosolic factor 2 & 2.4 & 2.7 & 1.2 \\
\hline NM_005863 & NET1 & Neuroepithelial cell transforming 1 & 2.3 & 3.9 & 1.4 \\
\hline NM_003489 & NRIP1 & Nuclear receptor interacting protein 1 & 2.1 & 2.1 & 1.3 \\
\hline NM_020190 & OLFML3 & Olfactomedin-like 3 & 2.8. & 7.3 & 1.2 \\
\hline NM_002564 & P2RY2 & Purinergic receptor P2Y, G-protein coupled, 2 & 2.2 & 4.5 & 2.0 \\
\hline NM_006474 & PDPN & Podoplanin & 2.0 & 3.1 & 2.1 \\
\hline NM_001134438 & PHLDB2 & Pleckstrin homology-like domain, family B, member 2 & 1.8 & ND & ND \\
\hline NM_012417 & PITPNC1 & Phosphatidylinositol transfe r protein, cytoplasmic 1 & 1.8 & ND & ND \\
\hline NM_000930 & PLAT & Plasminogen activator, tissue & 2.1 & - & 1.6 \\
\hline NM_032726 & PLCD4 & Phospholipase C, $\delta 4$ & 2.0 & 3.6 & 2.0 \\
\hline NM_015993 & PLLP & Plasma membrane proteolipid (plasmolipin) & 1.9 & 2.9 & 2.5 \\
\hline NM_001017368 & RFFL & Ring finger and FYVE-like domain containing 1 & 1.8 & ND & ND \\
\hline NM_003003 & SEC14L1 & SEC14-like 1 (Saccharomyces cerevisiae); SEC14-like 1 pseudogene & 2.0 & 2.1 & \\
\hline NM_004636 & SEMA3B & Semaphorin 3B & 2.0 & 11.9 & 4.2 \\
\hline NM_030666 & SERPINB1 & Serpin peptidase inhibitor, clade B (ovalbumin), member 1 & 6.9 & 17.9 & 1.7 \\
\hline NM_004170 & SLC1A1 & Solute carrier family 1 , member 1 & 1.9 & 62.6 & 3.6 \\
\hline NM_152697 & SLC44A5 & Solute carrier family 44 , member 5 & 2.1 & - & 2.5 \\
\hline NM_003615 & SLC4A7 & Solute carrier family 4 , sodium bicarbonate cotransporter, member 7 & 2.2 & 1.9 & 1.2 \\
\hline NM_007231 & SLC6A14 & Solute carrier family 6 (amino acid transporter), member 14 & 2.7 & - & 1.4 \\
\hline NM_014467 & SRPX2 & Sushi-repeat-containing protein, $\mathrm{X}$-linked 2 & 1.8 & - & 1.5 \\
\hline NM_003238 & TGFB2 & Transforming growth factor, $\beta 2$ & 3.0 & 6.0 & 1.7 \\
\hline NM_000361 & THBD & Thrombomodulin & 2.0 & 3.9 & 2.3 \\
\hline NM_022164 & TINAGL1 & Tubulointerstitial nephritis antigen-like 1 & 2.0 & 2.9 & 1.5 \\
\hline NM_024943 & TMEM156 & Transmembrane protein 156 & 3.5 & 26.3 & 7.0 \\
\hline NM_001042595 & TMEM91 & Transmembrane protein 91 & 2.4 & 6.0 & 2.2 \\
\hline NM_003330 & TXNRD1 & Thioredoxin reductase 1; hypothetical LOC100130902 & 2.8 & 3.7 & 1.6 \\
\hline NR_015379 & UCA1 & Urothelial cancer associated 1 (non-protein coding) & 3.4 & ND & ND \\
\hline
\end{tabular}

\section{Figure 2}

Catalog of candidates upregulated in human primary keratinocytes in response to $200 \mathrm{nM}$ calcitriol treatment compared with response to $1 \mathrm{nM}$ calcitriol. Although 67 genes were demonstrated to be upregulated within our global microarray study, only the most promising were selected for subsequent RTq-PCR confirmation. Genes that demonstrated $\geq 1$.8-fold induction and $P<0.05$ within our $200 \mathrm{nM}$ RTq-PCR approach are highlighted in light gray. Genes that have previously been identified as (putative) calcitriol targets in various cell lines are portrayed in bold. New targets (to the best of our knowledge neither described in single-gene nor in genome-wide approaches) fulfilling our stringent criteria are shown in dark gray. ND, not determined (not explicitly chosen for RTq-PCR confirmation); -, not listed due to a fold-change $<1.8$ or statistically insignificant in $200 \mathrm{nM} / 16 \mathrm{~h}$ RTq-PCR.

Published by Bioscientifica Ltd 


\begin{tabular}{|c|c|c|c|c|c|}
\hline & & & MA & RTq- & \\
\hline & & & & $200 \mathrm{nM} / 16 \mathrm{~h}$ & $1 \mathrm{nM} / 8 \mathrm{~h}$ \\
\hline GenBank & Symbol & Gene description & Fold & Fold & Fold \\
\hline NM_133265 & AMOT & Angiomotin & -1.8 & ND & ND \\
\hline NM_153000 & $A P C D D 1$ & Adenomatosis polyposis coli down-regulated 1 & -2.0 & - & -1.4 \\
\hline NM_003986 & $B B O X 1$ & $\begin{array}{l}\text { Butyrobetaine }(\gamma), 2 \text {-oxoglutarate dioxygenase } \\
\text { ( } \gamma \text {-butyrobetaine hydroxylase }) 1\end{array}$ & -2.3 & - & 1.1 \\
\hline NM_016352 & CPA4 & Carboxypeptidase A4 & -2.9 & -3.3 & -1.5 \\
\hline NM_001878 & CRABP2 & Cellular retinoic acid binding protein 2 & -2.4 & -3.0 & -1.3 \\
\hline NM_004887 & CXCL14 & Chemokine (C-X-C motif) ligand 14 & -4.7 & -5.6 & -1.6 \\
\hline NM_000779 & CYP4B1 & Cytochrome P450, family 4 , subfamily B, polypeptide 1 & -1.9 & -2.9 & -1.1 \\
\hline NM_004948 & $D S C 1$ & Desmocollin 1 & -2.0 & - & -1.2 \\
\hline NM_001942 & DSG1 & Desmoglein 1 & -2.3 & - & -1.3 \\
\hline NM_014375 & FETUB & Fetuin B & -2.2 & -4.3 & -1.4 \\
\hline NM_006121 & KRT1 & Keratin 1 & -3.0 & - & \\
\hline NM_000421 & KRT10 & Keratin 10 & -2.1 & - & \\
\hline NM_018192 & LEPREL1 & Leprecan-like 1 & -1.8 & -2.7 & -3.2 \\
\hline NM_001102469 & LIPN & Lipase, family member $\mathrm{N}$ & -1.8 & - & -2.2 \\
\hline NM_014033 & METTL7A & Methyltransferase like 7A & -2.6 & - & -1.1 \\
\hline NM_002974 & SERPINB4 & Serpin peptidase inhibitor, clade B (ovalbumin), member 4 & -2.0 & - & -1.3 \\
\hline NM_205841 & SPINK6 & Serine peptidase inhibitor, Kazal type 6 & -1.8 & ND & \\
\hline NM_020431 & TMEM63C & Transmembrane protein $63 \mathrm{C}$ & -2.4 & -4.8 & \\
\hline NM_003810 & TNFSF10 & Tumor necrosis factor (ligand) superfamily, member 10 & -2.0 & - & -1.1 \\
\hline
\end{tabular}

Figure 3

Catalog of candidates downregulated in human foreskin-derived primary keratinocytes in response to $1 \mathrm{nM}$ vs $200 \mathrm{nM}$ calcitriol exposure. For detailed color code description, refer to the caption of Fig. 2.

\section{The majority of validated calcitriol response genes contain (predicted) VDR binding elements within their promoter regions}

To evaluate whether both induced and repressed candidates represent direct, i.e. primary, VDR targets, their promoter regions were analyzed for the presence of (putative) response elements, an essential prerequisite for positioning calcitriol-bound VDR-RXR heterodimers close to the basal transcription machinery (Toell et al. 2000, Shaffer \& Gewirth 2002). The internet-based software tool MatInspector employed for this purpose accurately calculates theoretical nuclear hormone receptor superfamily binding preferences, which are expressed as positional weight matrices (Cartharius et al. 2005). The nucleotide frequency templates applied comprise DR3 (random expectation: 0.14 matches per $1000 \mathrm{bps}$ ), bipartite DR3 (random expectation: 0.01 matches per $1000 \mathrm{bps}$ ), DR4 (random expectation: 0.07 matches per $1000 \mathrm{bps}$ ), and DR5 (random expectation: <0.01 matches per $1000 \mathrm{bps)}$ arrangements. In this analysis, of our 55 RTq-PCRvalidated candidates, 50 - including some established constituents for which definite VDREs have already been characterized - were found to explicitly contain at least one response element occurring without positional bias relative to the TSS (Fig. 4). As highlighted in Fig. 1, the majority of genes carry either (bipartite) DR3 (63.5\%) or DR4 (27.3\%) motifs. As speculative binding sites are not sufficient to indicate definite functionality, we performed in vitro electrophoretic mobility agarose gel shift assays using a combination of predicted, PCR-amplified promoter regions of some randomly selected differentially expressed calcitriol response genes, plus recombinantly expressed and purified hexahistidine-tagged VDR DBD. Figure 5 shows the obtained results for CRABP2, OLFML3, BNC2, TMEM91, and KRT19 in relation to an osteopontinpositive control DR3 containing PCR product (47.5\% shift under our experimental conditions, as visible by a densitometrically quantified decrease in the amount of input DNA upon VDR DNA-BD addition, leading to a smear-like displacement) and four analogously treated negative controls not containing any VDREs. We observed definite gel shifts for CRABP2 (33.5\% shift), OLFML3 (33.5\%), and BNC2 (31.9\%) promoters, whereas TMEM91 (14.9\%) and KRT19 (10.45) lingered considerably inferior. This test set, although to be refined and further extended in follow-up approaches, is a preliminary incidence of definite biological functionality of a realistic amount of predicted response elements in vitro. 
Table 1 Interindividual variation of gene expression investigated by RTq-PCR. The mean interindividual variance (IV), the percentaged relative S.D. across individuals in the calcitriolstimulated or ethanol-treated control group, was experimentally determined to be $\sim 10 \%$ for the $200 \mathrm{nM}$ calcitriol $/ 16 \mathrm{~h}$ and the $1 \mathrm{nM}$ calcitriol/8 $\mathrm{h}$ configurations. The data therefore are considered to be highly reliable

\begin{tabular}{|c|c|c|c|c|}
\hline \multirow[b]{3}{*}{ Symbol } & \multicolumn{4}{|l|}{ IV (\%) } \\
\hline & \multicolumn{2}{|c|}{$200 \mathrm{nM} / 16 \mathrm{~h}$} & \multicolumn{2}{|l|}{$1 \mathrm{nM} / 8 \mathrm{~h}$} \\
\hline & Calcitriol & $\mathrm{EtOH}$ & Calcitriol & EtOH \\
\hline$A B C A 1$ & 2.4 & 3.2 & 10.4 & 9.8 \\
\hline$A B H D 3$ & 3.9 & 3.1 & 16.5 & 12.6 \\
\hline AKAP12 & 14.8 & 6.7 & 16.7 & 16.7 \\
\hline$A P C D D 1$ & 7.7 & 5.2 & 7.5 & 9.2 \\
\hline$B B O \times 1$ & 5.2 & 1.7 & 4.1 & 12.9 \\
\hline$B N C 2$ & 7.0 & 12.7 & 4.7 & 7.9 \\
\hline$C A B 39$ & 4.2 & 8.5 & 9.2 & 15.2 \\
\hline$C A L B 2$ & 10.2 & 2.4 & 7.2 & 4.9 \\
\hline$C D 14$ & 15.8 & 9.7 & & \\
\hline$C D 274$ & 6.0 & 6.5 & 8.7 & 9.9 \\
\hline CD97 & 4.2 & 3.1 & 8.7 & 6.8 \\
\hline$C D A$ & 4.5 & 9.2 & 6.8 & 12.5 \\
\hline CHST11 & 7.3 & 7.9 & 4.5 & 7.5 \\
\hline CLDN7 & 9.6 & 11.4 & 14.9 & 13.9 \\
\hline$C L M N$ & 8.1 & 4.5 & 3.3 & 7.8 \\
\hline CPA4 & 3.6 & 7.9 & 13.5 & 19.1 \\
\hline$C R A B P 2$ & 3.5 & 6.5 & 13.3 & 8.8 \\
\hline CXCL14 & 31.1 & 43.6 & 15.4 & 15.7 \\
\hline CYP24A1 & 2.0 & & & \\
\hline CYP3A5 & 0.7 & 8.8 & 13.8 & 12.3 \\
\hline CYP4B1 & 7.3 & 5.8 & 5.6 & 1.6 \\
\hline CYP4F11 & 13.9 & 21.6 & 8.2 & 4.9 \\
\hline CYP4F3 & 9.6 & 9.4 & 1.5 & 3.2 \\
\hline DHRS9 & 6.7 & 4.0 & 4.9 & 7.1 \\
\hline$D S C 1$ & 22.6 & 15.2 & 14.0 & 17.7 \\
\hline DSG1 & 26.6 & 18.7 & 18.3 & 22.2 \\
\hline DUSP10 & 4.8 & 2.9 & 3.6 & 3.9 \\
\hline EFTUD1 & 2.9 & 8.0 & 15.2 & 12.3 \\
\hline$E T N K 2$ & 6.6 & 3.3 & 3.3 & 3.0 \\
\hline$F A M 129 A$ & 9.4 & 11.4 & 19.4 & 17.6 \\
\hline FETUB & 6.7 & 4.7 & 9.8 & 9.2 \\
\hline GOS2 & 12.3 & 11.4 & 46.5 & 59.7 \\
\hline G6PD & 32.3 & 20.6 & 5.5 & 6.0 \\
\hline GPCPD1 & 11.1 & 2.3 & & \\
\hline HBEGF & 17.5 & 13.5 & 3.1 & 7.1 \\
\hline HCAR3 & 2.5 & 2.4 & 0.4 & 3.1 \\
\hline ID1 & 3.2 & 18.1 & 4.2 & 5.9 \\
\hline IGFL3 & 30.3 & 1.2 & 25.1 & 25.4 \\
\hline$I L 1 B$ & 31.8 & 32.0 & 8.5 & 9.6 \\
\hline IL1RL1 & 13.8 & 16.0 & & \\
\hline$K L H L 5$ & 3.7 & 4.4 & 10.1 & 15.9 \\
\hline$K L K 13$ & 8.3 & 6.2 & 2.3 & 4.3 \\
\hline$K L K 6$ & 21.8 & 14.1 & 3.4 & 1.7 \\
\hline$K R T 1$ & 7.3 & 6.4 & & \\
\hline KRT10 & 19.5 & 23.7 & 16.1 & 13.9 \\
\hline KRT19 & 63.4 & 15.2 & 23.9 & 15.6 \\
\hline LEPREL 1 & 5.1 & 15.7 & 17.1 & 36.2 \\
\hline LIPN & 5.4 & 3.3 & 3.5 & 16.7 \\
\hline
\end{tabular}

http://jme.endocrinology-journals.org DOI: 10.1530/JME-11-0191
Table 1 Continued

\begin{tabular}{|c|c|c|c|c|}
\hline \multirow[b]{3}{*}{ Symbol } & \multicolumn{4}{|l|}{ IV (\%) } \\
\hline & \multicolumn{2}{|c|}{$200 \mathrm{nM} / 16 \mathrm{~h}$} & \multicolumn{2}{|l|}{$1 \mathrm{nM} / 8 \mathrm{~h}$} \\
\hline & Calcitriol & EtOH & Calcitriol & EtOH \\
\hline LYPD5 & 7.9 & 18.9 & 32.2 & 30.3 \\
\hline METTL7A & 9.9 & 9.6 & 4.8 & 3.8 \\
\hline MPV17L & 5.2 & 10.5 & & \\
\hline NCF2 & 4.8 & 9.9 & 2.8 & 4.8 \\
\hline NET1 & 24.2 & 6.5 & 23.2 & 25.5 \\
\hline NRIP1 & 0.7 & 1.6 & 14.0 & 16.7 \\
\hline OLFML3 & 13.9 & 2.9 & 16.6 & 14.4 \\
\hline$P 2 R Y 2$ & 4.6 & 3.4 & 3.9 & 4.3 \\
\hline$P D P N$ & 25.9 & 10.6 & 27.1 & 18.2 \\
\hline PLAT & 0.7 & 10.2 & 5.7 & 2.6 \\
\hline PLCD4 & 5.7 & 8.5 & 5.7 & 5.2 \\
\hline PLCXD2 & 0.7 & 3.4 & 3.3 & 5.9 \\
\hline PLLP & 4.0 & 4.0 & 6.4 & 11.8 \\
\hline SEC14L1 & 3.1 & 4.7 & & \\
\hline SEMA3B & 7.5 & 12.1 & 7.0 & 4.9 \\
\hline SERPINB1 & & 22.8 & 8.1 & 7.4 \\
\hline SERPINB4 & 5.0 & 26.1 & 12.8 & 15.2 \\
\hline SLC1A1 & 6.1 & 7.3 & 16.0 & 13.7 \\
\hline SLC44A5 & 4.7 & 1.7 & 9.5 & 5.4 \\
\hline$S L C 4 A 7$ & 10.4 & 4.5 & 8.7 & 11.5 \\
\hline SLC6A14 & 7.7 & 6.9 & 0.9 & 3.9 \\
\hline SRPX2 & 11.5 & 4.1 & 12.5 & 14.1 \\
\hline TGFB2 & 9.9 & 13.5 & 5.4 & 9.9 \\
\hline$T H B D$ & 10.1 & 6.3 & 9.0 & 7.6 \\
\hline TINAGL1 & 3.1 & 6.6 & 7.2 & 9.5 \\
\hline TMEM156 & 2.9 & 4.6 & 5.4 & 9.2 \\
\hline TMEM63C & 2.0 & 10.9 & & \\
\hline TMEM91 & 4.3 & 10.0 & 10.0 & 8.4 \\
\hline TNFSF10 & 8.7 & 14.6 & 5.4 & 7.0 \\
\hline TXNRD1 & 23.5 & 13.3 & 13.1 & 14.5 \\
\hline Mean IV (\%) & 10.2 & 9.7 & 10.4 & 11.6 \\
\hline
\end{tabular}

Apart from a large assortment of single-gene investigations, several medium-scale to HTP global transcriptomic studies have been performed for deciphering (classical) calcitriol target genes and concomitant pathways (summarized in Fig. 6). The most important examples encompass primary, immortalized, or malignant prostate (Krishnan et al. 2004, Peehl et al. 2004, Kovalenko et al. 2010, Wang et al. 2011), colon (Wood et al. 2004), squamous cell carcinoma (Akutsu et al. 2001, Lin et al. 2002, Wang et al. 2005), myelocytic/monocytic leukemia (Savli et al. 2002, Suzuki et al. 2006, Heikkinen et al. 2011), ovarian (Zhang et al. 2005), coronary artery smooth muscle (Wu-Wong et al. 2006), (pre-) adipocytic (Sun et al. 2008), lymphoblastoid (Ramagopalan et al. 2010), or breast cancer (Swami et al. 2003, Kriebitzsch et al.

Published by Bioscientifica Ltd. 


\begin{tabular}{|c|c|c|c|c|c|c|c|}
\hline Gene & Matrix family & From & To & $\begin{array}{l}\text { Anch } \\
\text { or }\end{array}$ & Matrix sim. & Strand & Consensus sequence \\
\hline \multirow[t]{4}{*}{$A B C A 1$} & DR4 & 276 & 300 & 288 & 0.809 & + & ggagggtcaggga \\
\hline & $\overline{\mathrm{DR} 3}$ & 512 & 536 & 524 & 0.858 & + & cactttgggagg \\
\hline & $\overline{\mathrm{DR} 3}$ & 1297 & 1321 & 1309 & 0.862 & - & GTGGgcagctc \\
\hline & DR3 & 2432 & 2456 & 2444 & 0.877 & - & ggggtgaggggalagGCGGacagtcc \\
\hline ABHD3 & Bipartite DR3 & 1479 & 1503 & 1491 & 0.831 & + & Caacatggtgaaacc \\
\hline \multirow[t]{4}{*}{ AKAP12 } & DR3 & 2323 & 2347 & 2335 & 0.854 & + & ttccccgggggaagGGGGgcggcta \\
\hline & Bipartite DR3 & 2639 & 2663 & 2651 & 0.819 & - & aatgatgGATCacccalaggcaggag \\
\hline & DR4 & 2771 & 2795 & 2783 & 0.821 & + & acggGAGGcgeccgaggglccgggtg \\
\hline & $\overline{\text { DR4 }}$ & 2917 & 2941 & 2929 & 0.817 & + & gcggaggctaagag \\
\hline \multirow[t]{2}{*}{ BNC2 } & Bipartite DR3 & 4249 & 4273 & 4261 & 0.800 & - & tcattggGGTCatcatcttcatcat \\
\hline & DR5 & 5842 & 5866 & 5854 & 0.829 & + & gcAGGAtagtgc \\
\hline \multirow[t]{2}{*}{ CAB39 } & DR4 & 2730 & 2754 & 2742 & 0.802 & + & cagagaagggaacgcc \\
\hline & $\overline{\text { DR4 }}$ & 2819 & 2843 & 2831 & 0.808 & - & gcaggcg \\
\hline \multirow[t]{4}{*}{ CALB2 } & Bipartite DR3 & 325 & 349 & 337 & 0.858 & + & Caaagaggttaaata \\
\hline & DR3 & 576 & 600 & 588 & 0.877 & + & gtttaaaggtcactGTGGccaccct \\
\hline & DR3 & 734 & 758 & 746 & 0.871 & - & tgtgttgggtgagaGAGCtcatccc \\
\hline & Bipartite DR3 & 1295 & 1319 & 1307 & 0.821 & - & gtgggcaGATCalcgaggttaalgaga \\
\hline CD14 & Bipartite DR3 & 2989 & 3013 & 3001 & 0.812 & + & ccgaagaGTTCacaagtgtgalagcc \\
\hline \multirow[t]{4}{*}{ CD274 } & DR3 & 627 & 651 & 639 & 0.919 & - & ggggcagggtcttgGAGGtcaacat \\
\hline & Bipartite DR3 & 1291 & 1315 & 1303 & 0.821 & + & attcataGATCatccaggccatcta \\
\hline & Bipartite DR3 & 1735 & 1759 & 1747 & 0.816 & - & cttttgaGGTCacatagtagaatag \\
\hline & DR3 & 2127 & 2151 & 2139 & 0.891 & + & cacttgaggtcalagGAGTtcgagaa \\
\hline \multirow[t]{2}{*}{ CDA } & Bipartite DR3 & 1702 & 1726 & 1714 & 0.809 & - & cagccaaGATCacatagggcagaac \\
\hline & Bipartite DR3 & 2061 & 2085 & 2073 & 0.885 & + & aactgtg GTTCagggaggtcalagtg \\
\hline \multirow[t]{4}{*}{ CHST11 } & DR3 & 184 & 208 & 196 & 0.854 & + & gaggtcaggagatcGAGAccatcct \\
\hline & Bipartite DR3 & 1344 & 1368 & 1356 & 0.905 & + & ggtgagaGGTCacttgggtgacctg \\
\hline & DR4 & 1505 & 1529 & 1517 & 0.812 & + & gtggGGAGgtggggagggtgcagtg \\
\hline & DR3 & 2423 & 2447 & 2435 & 0.918 & - & gagtcggggttaaaGAGGgctgact \\
\hline \multirow[t]{4}{*}{ CLDN7 } & DR3 & 108 & 132 & 120 & 0.854 & + & aaggtcaggagatcGAGAccatcct \\
\hline & DR4 & 924 & 948 & 936 & 0.832 & + & ttggGAGGitcgaggitgggttgggat \\
\hline & DR4 & 1397 & 1421 & 1409 & 0.831 & + & ctgaGAAGtatgaggaggttggagg \\
\hline & DR5 & 2218 & 2242 & 2230 & 0.818 & - & agcagggtgagggctAGGTcagagt \\
\hline \multirow[t]{4}{*}{ CLMN } & DR4 & 544 & 568 & 556 & 0.842 & + & tggaGAAGtctctgaggtgcacatg \\
\hline & Bipartite DR3 & 692 & 716 & 704 & 0.877 & + & actgctgGGTCaaaaagtgtagagc \\
\hline & Bipartite DR3 & 1450 & 1474 & 1462 & 0.806 & - & aaggtggGATCagtggagacagaag \\
\hline & DR5 & 1726 & 1750 & 1738 & 0.805 & - & atggaggtcccccgaAGGAcagacc \\
\hline CYP3A5 & Bipartite DR3 & 1892 & 1916 & 1904 & 0.800 & + & aactggaGGTCatcatgttaagtga \\
\hline \multirow[t]{2}{*}{ CYP4F3 } & DR3 & 2149 & 2173 & 2161 & 0.901 & - & tagcgggggacaatGAGGgctccta \\
\hline & DR4 & 3012 & 3036 & 3024 & 0.814 & + & gagaGGAGgttgtgígggacaaggt \\
\hline \multirow[t]{2}{*}{ DHRS9 } & $\overline{\text { DR4 }}$ & 106 & 130 & 118 & 0.820 & - & gtgaGAAGtattatatggggaatta \\
\hline & DR4 & 1094 & 1118 & 1106 & 0.816 & + & atctGAAGtcaatgtaggatgagtt \\
\hline \multirow[t]{3}{*}{ DUSP10 } & DR4 & 368 & 392 & 380 & 0.804 & - & aggcGGGGtgggcaggggggtggggc \\
\hline & $\overline{\text { DR4 }}$ & 583 & 607 & 595 & 0.861 & + & aggg $\overline{\mathbf{G}}$ AAGtgagggitgggatgagcc \\
\hline & DR3 & 2274 & 2298 & 2286 & 0.861 & - & ccgtcccggacaggGAGGcccttca \\
\hline \multirow[t]{2}{*}{ EFTUD1 } & DR3 & 341 & 365 & 353 & 0.854 & + & aaagtcaggagatcGAGAccatcct \\
\hline & $\overline{\text { DR3 }}$ & 1422 & 1446 & 1434 & 0.953 & + & gaggtcaggagatgGAGGccaacat \\
\hline \multirow[t]{7}{*}{ ETNK2 } & DR3 & 5 & 29 & 17 & 0.866 & - & ctgcctgggtggcaGAGGgcctcag \\
\hline & DR4 & 492 & 516 & 504 & 0.811 & + & cagaagccagctctgaGTTCagact \\
\hline & DR4 & 544 & 568 & 556 & 0.893 & - & gaggGGAGttttgcagggacaagag \\
\hline & DR3 & 691 & 715 & 703 & 0.868 & + & caggtggggaaactGAGGcccagag \\
\hline & DR4 & 1466 & 1490 & 1478 & 0.813 & + & ttgaGAGGccgaggagggtggatca \\
\hline & DR4 & 2945 & 2969 & 2957 & 0.800 & + & cgggGGCGttcccgcgggccaccgc \\
\hline & DR4 & 3078 & 3102 & 3090 & 0.867 & - & gggaGTGGtagaggaggggccaggg \\
\hline \multirow{3}{*}{$\begin{array}{l}\text { FAM129A } \\
\text { G0S2 }\end{array}$} & DR3 & 547 & 571 & 559 & 0.861 & - & gagatcaggagatgGAGAccatcct \\
\hline & $\overline{\mathrm{DR3}}$ & 118 & 142 & 130 & 0.936 & - & agacacaggggaaaGAGGtcttttg \\
\hline & Bipartite DR3 & 2488 & 2512 & 2500 & 0.824 & - & ggcaatgGATCagagaggaglaggc \\
\hline
\end{tabular}

Figure 4 (continued) 


\begin{tabular}{|c|c|c|c|c|c|c|c|}
\hline GPCPD1 & DR5 & 1737 & 1761 & 1749 & 0.824 & - & gtggaggttacagtgAGCTgagatc \\
\hline & DR3 & 2846 & 2870 & 2858 & 0.864 & + & ctgagaagggcagcGGGGacacggg \\
\hline HCAR3 & Bipartite DR3 & 33 & 57 & 45 & 0.831 & - & ccagcctGGTCaacatggtgalatc \\
\hline \multirow[t]{2}{*}{ ID1 } & Bipartite DR3 & 1705 & 1729 & 1717 & 0.866 & + & tattagg|GCTCagagagggcatgcg \\
\hline & Bipartite DR3 & 2925 & 2949 & 2937 & 0.864 & - & ggggcggGCTCagaacgttcaaaag \\
\hline IGFL3 & DR5 & 2801 & 2825 & 2813 & 0.801 & - & tttgaggtgactagtAGGGcacagg \\
\hline IL1RL1 & Bipartite DR3 & 734 & 758 & 746 & 0.844 & + & aaagctgGTTCaatgagcttagatt \\
\hline \multirow[t]{16}{*}{ KLK13 } & DR5 & 147 & 171 & 159 & 0.804 & - & gctctggttgaagtgAGGTcatgga \\
\hline & DR5 & 211 & 235 & 223 & 0.807 & - & tgaggggtgagtgccAGGTcaaatt \\
\hline & DR4 & 443 & 467 & 455 & 0.826 & + & ctgtGAGGtgggagaa \\
\hline & $\overline{\text { DR4 }}$ & 452 & 476 & 464 & 0.821 & + & tccaggg \\
\hline & DR5 & 476 & 500 & 488 & 0.821 & - & ctcaaggtgaaagaaAGGTcactgt \\
\hline & Bipartite DR3 & 507 & 531 & 519 & 0.818 & - & tggtgggGGTGagctgggtcatacc \\
\hline & DR4 & 685 & 709 & 697 & 0.802 & - & gatigGGAGgtatctagggataagtt \\
\hline & $\overline{\text { DR5 }}$ & 975 & 999 & 987 & 0.830 & - & aagtggctcaaagacAGGAaanggt \\
\hline & DR3 & 1672 & 1698 & 1684 & 0.880 & - & cagagggggtgaggGAGTccacggg \\
\hline & $\overline{\text { DR4 }}$ & 2115 & 2139 & 2127 & 0.827 & + & ggttGAAGttagggatts \\
\hline & $\overline{\text { DR5 }}$ & 2144 & 2168 & 2156 & 0.801 & + & agcggg \\
\hline & DR4 & 2342 & 2366 & 2354 & 0.800 & + & gagaGG \\
\hline & $\overline{\text { DR3 }}$ & 2376 & 2400 & 2388 & 0.865 & + & tgagctgggggaggGAGTtcagggg \\
\hline & DR3 & 2503 & 2527 & 2525 & 0.878 & + & cggaggagggcaggGAGGggagaga \\
\hline & Bipartite DR3 & 3049 & 3073 & 3061 & 0.804 & - & gggaggcGATCactagggccagggg \\
\hline & DR3 & 3061 & 3085 & 3073 & 0.893 & - & aggccaaggtcaggGAGGcgatcac \\
\hline \multirow[t]{5}{*}{$\overline{K L K 6}$} & $\overline{\text { DR4 }}$ & 424 & 448 & 436 & 0.835 & + & gagaGAGGaggcagag \\
\hline & DR3 & 513 & 537 & 525 & 0.860 & + & gtgctgaggtcagtGGGGaccaaat \\
\hline & $\overline{\text { DR4 }}$ & 1094 & 1118 & 1106 & 0.841 & - & ctggGCAGtagcagaggc \\
\hline & DR3 & 2227 & 2251 & 2239 & 0.904 & + & ctcctggggacalcaGAGGtcggcag \\
\hline & Bipartite DR3 & 2857 & 2881 & 2869 & 0.877 & + & ggtcaggGGTCaccaaglagcagagc \\
\hline \multirow[t]{5}{*}{ KRT19 } & DR4 & 155 & 179 & 167 & 0.824 & - & cagaGATGgaactggaggtcaagct \\
\hline & DR3 & 761 & 785 & 773 & 0.874 & + & ctctgaaggttaggGAGCtcagaac \\
\hline & Bipartite DR3 & 1452 & 1476 & 1464 & 0.891 & + & ggacgggGGTCactggggacaggaa \\
\hline & Bipartite DR3 & 2387 & 2411 & 2399 & 0.831 & + & ccagcctGGTCaacatggtgaaacc \\
\hline & DR5 & 2834 & 2858 & 2846 & 0.809 & + & cctctggtctctgggAGGGgaggga \\
\hline \multirow[t]{3}{*}{ NCF2 } & DR5 & 701 & 725 & 713 & 0.803 & + & ttggcagtcagattaAGGAgaghttc \\
\hline & DR3 & 1750 & 1774 & 1762 & 0.857 & + & gaggggaggccgagGAGGccgaatc \\
\hline & Bipartite DR3 & 2586 & 2610 & 2598 & 0.808 & + & cactctaGGTCacgggtttcatttg \\
\hline \multirow[t]{3}{*}{ NET1 } & DR3 & 929 & 953 & 941 & 0.887 & - & gcaaagaggttaagGAGGgtatgaa \\
\hline & Bipartite DR3 & 2689 & 2713 & 2701 & 0.829 & - & ggaataaGTTCagtatggacaactt \\
\hline & Bipartite DR3 & 2825 & 2849 & 2837 & 0.867 & - & aagctgg $\mathbf{G}$ TCaagtaggacagaaa \\
\hline NRIP1 & Bipartite DR3 & 997 & 1021 & 1009 & 0.827 & + & attgggaGTTCagtaagaatatgtt \\
\hline \multirow[t]{2}{*}{ OLFML3 } & Bipartite DR3 & 579 & 603 & 591 & 0.848 & - & aaagcagGCTCagaatggccagaac \\
\hline & Bipartite DR3 & 2128 & 2152 & 2140 & 0.886 & - & gaggagtGTTCagtgagttcacact \\
\hline \multirow[t]{4}{*}{ P2RY2 } & DR3 & 49 & 73 & 61 & 0.875 & + & tggcctgggtcftcGAGGacccatg \\
\hline & DR3 & 867 & 891 & 879 & 0.891 & - & atcgetgggtticaGAGGccatcaa \\
\hline & DR4 & 2385 & 2409 & 2397 & 0.813 & + & gagtGGGGttgacgacagagaagag \\
\hline & Bipartite DR3 & 2404 & 2428 & 2416 & 0.832 & + & gaagagaGGTAalagcagctcalagat \\
\hline \multirow[t]{2}{*}{ PLCD4 } & DR3 & 2791 & 2815 & 2803 & 0.932 & + & ggattggggtcalatGAGGgctggca \\
\hline & Bipartite DR3 & 3076 & 3100 & 3088 & 0.849 & - & gctgtggGATCaggaagcccagcct \\
\hline \multirow[t]{3}{*}{ PLLP } & DR3 & 146 & 170 & 158 & 0.866 & - & atttctgggttaagGTGGtcaagga \\
\hline & Bipartite DR3 & 1563 & 1587 & 1575 & 0.807 & - & caccagaGGTCatgagittgagacc \\
\hline & Bipartite DR3 & 2167 & 2191 & 2179 & 0.865 & - & gaggaggGGTCactcagaagatggg \\
\hline \multirow[t]{6}{*}{ SEC14L1 } & Bipartite DR3 & 44 & 68 & 56 & 0.857 & + & gctgattGGTCagggaggaaatcat \\
\hline & DR4 & 209 & 233 & 221 & 0.840 & + & aggaGCAGtttagggagggtcagaa \\
\hline & DR4 & 548 & 573 & 560 & 0.800 & + & ggtgGAGGttgcagtgagccaagat \\
\hline & DR5 & 1599 & 1623 & 1611 & 0.800 & - & ttgggagtctgaggcAGGAgaatgg \\
\hline & DR3 & 1708 & 1732 & 1720 & 0.854 & - & gaggtcaggagatcGAGAccatcct \\
\hline & DR4 & 2555 & 2579 & 2567 & 0.817 & - & aaggGAAGtttgcgggaggtcaaaa \\
\hline
\end{tabular}

Figure 4 (continued)

http://jme.endocrinology-journals.org DOI: 10.1530/JME-11-0191
C 2013 Society for Endocrinology Printed in Great Britain 


\begin{tabular}{|c|c|c|c|c|c|c|c|}
\hline \multirow[t]{8}{*}{ SEMA3B } & DR4 & 301 & 325 & 313 & 0.853 & - & cctgGAAGtggaagtiggggctatgc \\
\hline & DR3 & 884 & 908 & 896 & 0.882 & - & taggggagggaglagGAGGglaggag \\
\hline & DR4 & 1546 & 1570 & 1558 & 0.816 & + & cggtGGAGtgtgaglalggcagccag \\
\hline & DR3 & 1579 & 1603 & 1591 & 0.862 & - & cttctcaggttctaGAGGtcttcca \\
\hline & Bipartite DR3 & 1958 & 1982 & 1970 & 0.841 & + & aaggccaGCTCagcgaggccaggag \\
\hline & DR3 & 2634 & 2658 & 2646 & 0.851 & - & tgtgaaaggggacaGAGTgccaaca \\
\hline & $\overline{\text { DR3 }}$ & 2908 & 2932 & 2920 & 0.851 & - & gccctaggggaaaGAGGctggggg \\
\hline & $\overline{\text { DR3 }}$ & 3051 & 3075 & 3063 & 0.802 & - & gctcagggtgctcaggGTTCagcgg \\
\hline \multirow[t]{2}{*}{ SERPINB1 } & $\overline{\text { DR3 }}$ & 1357 & 1381 & 1369 & 0.879 & + & agtgccaggaccctGAGGgcagaat \\
\hline & DR3 & 2433 & 2457 & 2445 & 0.850 & + & ggtgactggattatGAGGgcacctt \\
\hline \multirow[t]{2}{*}{$\overline{S L C 1 A 1}$} & DR3 & 1563 & 1587 & 1575 & 0.858 & - & gaggtcaggagattGAGAccatcct \\
\hline & DR3 & 2232 & 2256 & 2244 & 0.803 & + & atgctccagggectgTGGTcacaga \\
\hline \multirow[t]{2}{*}{ SLC4A7 } & $\overline{\text { DR4 }}$ & 198 & 222 & 210 & 0.806 & + & gagtGAAGagaccaagggatcaaat \\
\hline & Bipartite DR3 & 2196 & 2220 & 2208 & 0.829 & - & tctgataGTTCatcaaactcalacaa \\
\hline TGFB2 & $\overline{\text { DR3 }}$ & 2554 & 2578 & 2566 & 0.854 & + & aggagcaggagaagAGGgagctgg \\
\hline \multirow[t]{5}{*}{ THBD } & Bipartite DR3 & 28 & 52 & 40 & 0.841 & + & ggtgaagGGTCacaagtgcaalatgg \\
\hline & DR5 & 1243 & 1267 & 1255 & 0.827 & + & cagggggtccgcgtcAGGGgaggcg \\
\hline & DR4 & 1398 & 1422 & 1410 & 0.809 & + & ctggGGAGtgtgcggcgggacagtc \\
\hline & DR3 & 1656 & 1680 & 1668 & 0.855 & - & gggttaaggtgtagGAGCacagagt \\
\hline & DR4 & 2091 & 2115 & 2103 & 0.811 & + & tgtt_GGGGtgcaagaagcaccatcc \\
\hline \multirow[t]{6}{*}{ TINAGL1 } & Bipartite DR3 & 20 & 44 & 32 & 0.806 & + & cggaagg GCTCagaggg \\
\hline & DR3 & 189 & 213 & 201 & 0.854 & + & aaggtcaggagatcGAGAccatcct \\
\hline & DR5 & 438 & 462 & 450 & 0.824 & + & ctaggagtcactagg $\mathbf{A G}$ \\
\hline & Bipartite DR3 & 1655 & 1679 & 1667 & 0.811 & + & gactaagGGTGactaggggtaaagg \\
\hline & Bipartite DR3 & 2428 & 2452 & 2440 & 0.832 & + & aacaagg GATCaaagggtgcagagg \\
\hline & DR3 & 2435 & 2459 & 2447 & 0.866 & + & gatcaaagggtgcaGAGGccacccc \\
\hline \multirow{3}{*}{ TMEM156 } & DR3 & 54 & 78 & 66 & 0.862 & + & aaaactggggcgggGAGGccaggtg \\
\hline & DR4 & 107 & 131 & 119 & 0.870 & + & ttggGAGGttgaggtgggatgattg \\
\hline & DR4 & 679 & 703 & 691 & 0.836 & - & tagcGAAGtcaagtaag \\
\hline \multirow[t]{4}{*}{ TMEM91 } & $\underline{\mathrm{DR3}}$ & 246 & 270 & 258 & 0.894 & - & tttgggaggccttctGAGGtcaggag \\
\hline & DR4 & 821 & 845 & 833 & 0.806 & - & gatgGTGGtgacctgggg ccaagaa \\
\hline & DR4 & 1456 & 1480 & 1468 & 0.842 & - & ggcaGAAGttgcagtgggccgagat \\
\hline & DR4 & 1494 & 1518 & 1506 & 0.802 & - & tcggGAGGctgaggcaggacaatca \\
\hline \multirow[t]{2}{*}{ TXNRD1 } & DR3 & 1660 & 1684 & 1672 & 0.830 & + & atgaccctggttcatgGGTCattcg \\
\hline & Bipartite DR3 & 1669 & 1693 & 1681 & 0.842 & + & gttcatgGGTCattcggtagactaa \\
\hline CPA4 & DR3 & 2281 & 2305 & 2293 & 0.858 & - & gaggtcaggagattGAGAccatcct \\
\hline \multirow[t]{6}{*}{ CRABP2 } & Bipartite DR3 & 18 & 42 & 30 & 0.837 & - & ccgctggGATCaataaggagaagga \\
\hline & DR4 & 873 & 897 & 885 & 0.835 & + & cagtGAAGggaaggaggggcagcag \\
\hline & $\overline{\mathrm{DR3}}$ & 977 & 1001 & 989 & 0.870 & - & tgctgtaggtalagGAGGgggatta \\
\hline & $\overline{\text { DR3 }}$ & 1134 & 1158 & 1146 & 0.862 & - & ggcagcaggtcalagGAGCtctctga \\
\hline & Bipartite DR3 & 2031 & 2055 & 2043 & 0.801 & + & ttttacaGCTCaggatggtgacacc \\
\hline & $\underline{\mathrm{DR3}}$ & 2519 & 2543 & 2531 & 0.824 & + & ctggatccagttcagg TTCalgg \\
\hline \multirow[t]{3}{*}{ CXCL14 } & $\underline{\underline{D R 3}}$ & 104 & 128 & 116 & 0.865 & - & ctaactgggtgagg GAGGgggcttg \\
\hline & DR3 & 1803 & 1827 & 1815 & 0.809 & - & gaaataacttgtccaaGGTCacaga \\
\hline & DR4 & 2650 & 2674 & 2662 & 0.827 & - & tggaGAGGctgctgaagggcactgc \\
\hline \multirow[t]{3}{*}{ FETUB } & Bipartite DR3 & 126 & 150 & 138 & 0.852 & - & agggaga GATCagacaggtgagaca \\
\hline & DR4 & 1111 & 1135 & 1123 & 0.829 & + & ccgtGCAGtggaagaggtggaattt \\
\hline & Bipartite DR3 & 3059 & 3083 & 3071 & 0.843 & + & caggatgGGTCagtttgtggagctg \\
\hline
\end{tabular}

\section{Figure 4}

In silico prediction of putative VDR-RXR heterodimer binding sites within the promoter regions of RTq-PCR-validated calcitriol target genes. Columns specify applied matrix concepts, relative position/orientation with respect to the relevant TSS, calculated statistics, and matching consensus motifs. Marked in dark gray are the predicted (bipartite) DR3 elements that have been analyzed for definite recombinant VDR-DBD binding in agarose gel

2009, Vanoirbeek et al. 2009) (derived) cell lines. To date, only two studies have been truly devoted to 'healthy' skin cells. The first was accomplished by Lu et al. (2005) who profiled differential expression among 12600 constituents in HPV immortalized keratinocytes compared with shift assays. Nucleotides highlighted in black within the 'consensus sequence' column exhibit a high informational content, i.e. the matrix reveals high conservation (consensus index values $>60$ ) at this position. Nucleotides given in capital letters denote the core sequence routinely exploited by MatInspector.

'normal' human keratinocytes. The second study, by Moll et al. (2007), applied a set of 2135 sequence verified ESTs (explicitly enriched in transcription factors, signal transducers, and disease effectors) to identify calcitriolgoverned genes within foreskin-derived primary

Published by Bioscientifica Ltd. 


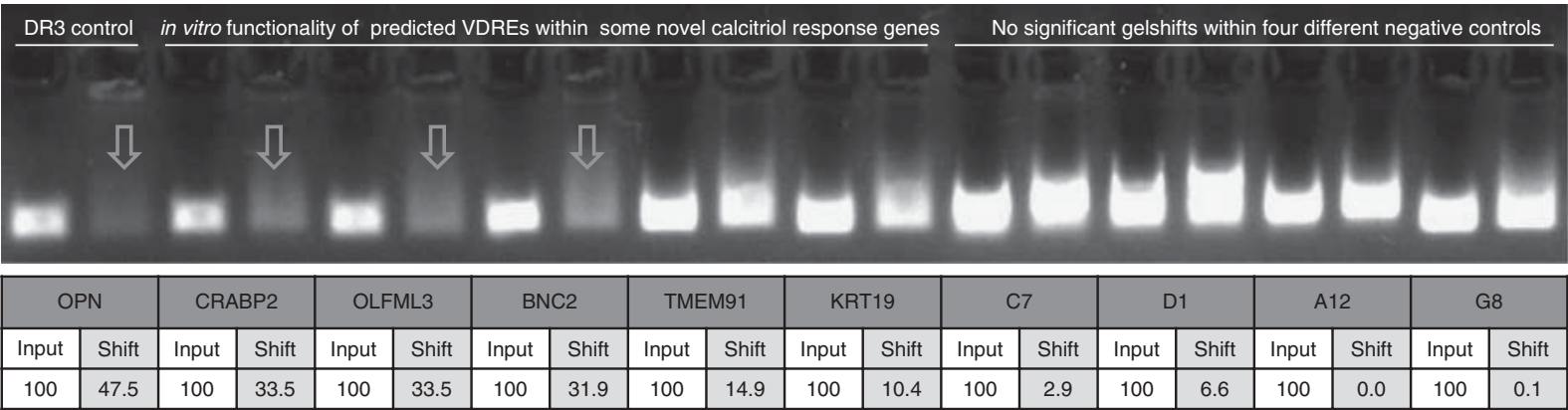

\section{Figure 5}

Electrophoretic mobility shift assays demonstrating the in vitro functionality of five MatInspector-predicted VDR-binding sites within some novel calcitriol response genes. Shown are PCR-amplified promoter fragments (denoted as input) for CRABP2, OLFML3, BNC2, TMEM91, and KRT19 in relation to osteopontin (OPN)-positive control and four different negative control PCR products designated as C7, D1, A12, and G8. Shown are the

keratinocytes. However, it is apparent from our literature survey that the basic strategies not only employed vastly diverse cell lines derived from numerous tissue models but also vary in application of in-house-prepared vs commercially available microarrays. Gene sets range from fairly restricted to genome spanning. There is significant variation in underlying sample labeling protocols, hybridization conditions, imaging quantification, and data filtering and interpretation (set cutoff values). Differences in detected differential regulation ranged from the per mill interval to as much as $7 \%$ (Moll et al. 2007) or $11.1 \%$ (Farach-Carson \& Xu 2002) of the investigated genes. These obvious disparities might, to a certain extent, be due to the fact that early efforts often lacked biological sample replication and statistical normalization necessary to eliminate false-positive artifacts. Because of cell-type and tissue-specific phenomena - tumor cells might exhibit reduced vitamin $\mathrm{D}$ responses, for instance, by displaying altered nuclear corepressor levels (Khanim et al. 2004) - or transient responses (Zhang et al. 2005, Carlberg \& Seuter 2009, Carlberg 2010), these parameters not only complicate direct mutual comparative assessments but might explain the limited agreement between the resultant catalogs of experimentally detected calcitriol targets (Tavera-Mendoza et al. 2006). Nonetheless, from the published studies, the number of reliable (primary) response genes can be estimated to range somewhere between 250 (Palmer et al. 2003, Carlberg 2010) and 1000 (Lin et al. 2002), not taking into account the plethora of secondary, delayed constituents that might contribute to the observable broad physiological actions. In one way or another, recognized targets appear implicated in cell cycle differences before (assumed as a 100\% PCR band intensity) and after addition of recombinant VDR-DBD. Actual shifts (obvious decreases in the amount of input DNA, leading to a smear-like appearance) in promoter (PCR band) intensity following DBD incubation are marked by arrows. Values calculated after ImageJ quantification are given below.

progression/arrest, transcriptional regulation, DNA replication, DNA repair, growth/proliferation, differentiation, apoptosis/survival, oxidative stress defense, immunity, barrier function, vitamin D metabolism, cell communication, lipid metabolism, cytoskeletal organization, cell adhesion, extracellular matrix constitution, membrane transport, and cytosolic $\mathrm{Ca}^{++} /$redox homeostasis, etc. all are inherent properties of both skin homeostasis and pathogenesis (White 2004, Tavera-Mendoza et al. 2006). Except for CYP24A1, an established marker of (metabolically time frame limited) calcitriol activity (Swami et al. 2003, Peehl et al. 2004, Wood et al. 2004, Zhang et al. 2005), only a handful of candidates have been identified by multiple research groups. Thus far, the available data fail to delineate the precise distribution, diversity, and entirety of affected targets, emphasizing the necessity to continue calcitriol-mediated gene expression studies if we are to be able to explain the entire spectrum of calcitriolprovoked activities.

In the current report, we present a substantially expanded 'hit list' of 55 specific calcitriol response genes that are differentially expressed upon calcitriol exposure within human primary keratinocytes isolated from three different individuals. Included are nine (16.36\%) calcitriol response genes previously known from human primary keratinocytes, as well as $46(83.6 \%)$ novel calcitriol response genes (33 of which have, parenthetically, previously been described in other settings) whose definite modulation was independently confirmed and statistically assessed. Our chosen calcitriol concentrations $(1 \mathrm{nM} / 200 \mathrm{nM})$ and stimulation times $(8 \mathrm{~h} / 16 \mathrm{~h})$ hereby represent a literature-based compromise between a 2 - and

Published by Bioscientifica Ltd. 


\begin{tabular}{|c|c|c|c|c|}
\hline Test system & Employed array platform & Obtained results & Overlap to our study & Reference \\
\hline \multirow[t]{3}{*}{$\begin{array}{l}\text { Squamous cell } \\
\text { carcinoma } \\
\text { lines }\end{array}$} & $\begin{array}{l}\text { Atlas Array with } 588 \text { genes (Clontech), } \\
\text { GF211 Named Human } 4000+\text { filters } \\
\text { (Research Genetics, Huntsville, AL, } \\
\text { USA) }\end{array}$ & $\begin{array}{l}38 \text { upregulated targets, including multiple } \\
\text { growth/transcription factors, adhesion } \\
\text { molecules, as well as kinases }\end{array}$ & None & $\begin{array}{l}\text { Austuk et al. } \\
(2001)\end{array}$ \\
\hline & $\begin{array}{l}\text { Affymetrix } 6800+\text { HuGene FL } \\
\text { human gene oligonucleotide chips }\end{array}$ & $\begin{array}{l}\text { Expression profiling with the low- } \\
\text { calcemic analog EB1089 identified } \\
89 \text { up- and } 63 \text { downregulated targets. } \\
\text { No evidence for gene- specific } \\
\text { differences in efficacy to calcitriol was } \\
\text { identified. Genes control signaling, } \\
\text { G protein-coupled receptor function, } \\
\text { redox balance, adhesion, cell cycle } \\
\text { progression, steroid metabolism, and } \\
\text { immune system functions }\end{array}$ & $\begin{array}{l}\text { CD14 } \uparrow, \text { SEC14L1 } \uparrow, \text { NET1 } \uparrow, \text { DUSP10 } \uparrow, \\
\text { G0S2 } \uparrow, \text { TXNRD1 } \uparrow, \text { TGFB2 } \uparrow\end{array}$ & $\begin{array}{l}\text { Lin et al. } \\
(2002)\end{array}$ \\
\hline & $\begin{array}{l}\text { Affymetrix Hu133A } 35000+ \\
\text { oligonucleotide arrays, combined } \\
\text { with screens for consensus DR3 } \\
\text { and ER6 elements }\end{array}$ & $\begin{array}{l}\text { Of } 913 \text { identified genes, } 734 \text { were } \\
\text { induced and } 179 \text { repressed. VDREs } \\
\text { lying within }-10 \text { to }+5 \mathrm{~kb} \text { relative to the } \\
5^{\prime} \text { TSS could be assigned to } 65 \% \text { of them }\end{array}$ & 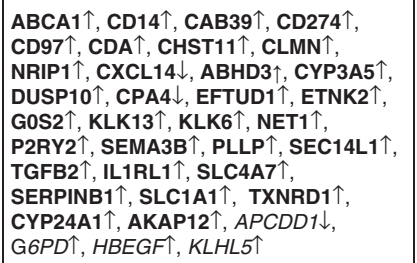 & $\begin{array}{l}\text { Wang et al. } \\
(2005)\end{array}$ \\
\hline \multirow[t]{2}{*}{$\begin{array}{l}\text { LnCaP prostate } \\
\text { cancer cells }\end{array}$} & $\begin{array}{l}\text { Stanford University in-house- } \\
\text { established array with } 23078 \\
\text { constituents (among them } 18433 \\
\text { sequenced clones) }\end{array}$ & $\begin{array}{l}18 \text { upregulated genes (with maximum } \\
\text { increases mostly seen at } 24 \mathrm{~h} \text { ), four } \\
\text { downregulated genes. Putative targets } \\
\text { appear to be involved in growth } \\
\text { regulation, DNA repair, differentiation, } \\
\text { cell-matrix interactions, membrane } \\
\text { transport, and inhibition of metastasis }\end{array}$ & None & $\begin{array}{l}\text { Krishnan et al. } \\
(2004)\end{array}$ \\
\hline & $\begin{array}{l}\text { Nimblegen human HG18-4plex whole- } \\
\text { genome microarray, Agilent human } \\
\text { miRNA v3 (Sanger release 12.0) } \\
\text { microarray }\end{array}$ & $\begin{array}{l}\text { Gene list containing } 1127 \text { entities that are } \\
\text { modulated by either testosterone (326), } \\
\text { calcitriol (825), or both compounds } \\
\text { additively }(280) \text {. Affected biological } \\
\text { processes encompass mitosis, DNA } \\
\text { repair/ recombination, elevation of } \\
\text { cytosolic } \mathrm{Ca}^{++} \text {, as well as } \\
\text { phosphoinositide-mediated signaling }\end{array}$ & $\begin{array}{l}\text { CD14 } \uparrow, \text { CD274 } \uparrow, \text { CLMN } \uparrow, \text { CYP24A1 } \uparrow, \\
\text { CYP3A5 } \uparrow, \text { KLK6 } \uparrow, \text { AKAP12 } \uparrow, \text { TGFB2 } \uparrow, \\
\text { EFTUD1 } 1, \text { SEC14L1 } 1 \text {, ABHD3 } \uparrow, \text { PLLP } \uparrow, \\
\text { DSC1 } \downarrow, \text { METTL7A } \downarrow, G 6 P D \uparrow, H B E G F \uparrow\end{array}$ & $\begin{array}{l}\text { Wang et al. } \\
\text { (2011) }\end{array}$ \\
\hline \multirow[t]{2}{*}{$\begin{array}{l}\text { Normal, } \\
\text { immortalized, or } \\
\text { malignant } \\
\text { prostate } \\
\text { epithelial cells }\end{array}$} & $\begin{array}{l}\text { Affymetrix U133 Plus } 2.0 \text { GeneChip } \\
\text { covering over } 47000 \text { transcripts plus } \\
\text { splice variants. Four analyses per } \\
\text { time and dose }\end{array}$ & $\begin{array}{l}1571,1816, \text { and } 3566 \text { transcript } \\
\text { level alterations at } 6,24, \text { and } 48 \mathrm{~h} \\
\text { at a } 5 \% \text { false discovery rate. } 288 \\
\text { genes were similarly targeted at all } \\
\text { time intervals (182 up-, } 80 \\
\text { downregulated) }\end{array}$ & 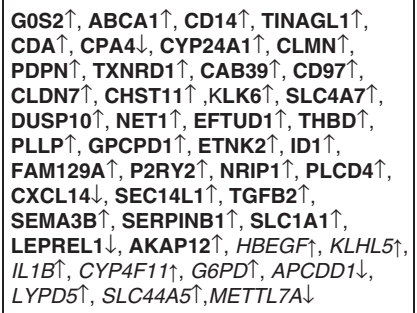 & $\begin{array}{l}\text { Kovalenko } \\
\text { et al. }(2010)\end{array}$ \\
\hline & $\begin{array}{l}\text { Array composed of } 24192 \text { spots } \\
\text { with } 23078 \text { elements containing } \\
\text { DNA. } 18433 \text { clones were } \\
\text { sequenced to verify their identity. } \\
\text { Over } 14000 \text { spots represented } \\
\text { uncharacterized ESTs }\end{array}$ & $\begin{array}{l}48 / 38 \text { genes upregulated and } 24 / 39 \\
\text { genes downregulated after } 6 / 24 \mathrm{~h} \text { of } \\
\text { calcitriol exposure in normal prostatic } \\
\text { epithelial cells. } 27 / 37 \text { genes upregulated } \\
\text { vs } 14 / 139 \text { genes downregulated in } \\
\text { prostate cancer-derived epithelial cells }\end{array}$ & $\begin{array}{l}\text { CYP24A1 } 1, \text { DUSP10 } \uparrow, \text { TXNRD1 } \uparrow, \\
\text { TGFB2 } \uparrow, \text { NET1 } \uparrow, \text { AKAP12 } \uparrow, \text { IL1RL1 } \uparrow, \\
\text { NRIP } \uparrow\end{array}$ & $\begin{array}{l}\text { Peehl, et al. } \\
(2004)\end{array}$ \\
\hline \multirow[t]{2}{*}{$\begin{array}{l}\text { MCF-7 and } \\
\text { MDA MB } 231 \\
\text { breast cancer } \\
\text { cell lines }\end{array}$} & $\begin{array}{l}\text { Array containing } 2000 \text { cancer- } \\
\text { related constituents representing } \\
18 \text { functional families (in-house } \\
\text { spotted in duplicates on four grids) }\end{array}$ & $\begin{array}{l}51 \text { upregulated (cell adhesion molecules, } \\
\text { kinases, steroid receptors,growth factors, } \\
\text { cytokines, and transcription factors) and } \\
19 \text { reliably downregulated genes }\end{array}$ & CYP24A1 $\uparrow$, TGFB2 $\uparrow$, TXNRD1 $\uparrow$ & $\begin{array}{l}\text { Swami et al. } \\
(2003)\end{array}$ \\
\hline & $\begin{array}{l}\text { Affymetrix human genome U133 } \\
\text { Plus } 2.0 \text { microarray }\end{array}$ & $\begin{array}{l}\text { Cluster containing } 142 \text { genes (involved } \\
\text { in lipid metabolism, apoptosis, } \\
\text { proliferation, transcription, cytoskeleton } \\
\text { organization, immune response, ECM } \\
\text { maintenance, transport, or ubiquitination) } \\
\text { upregulated by both calcitriol and a } \\
\text { superagonistic 17-methyl-D-ring } \\
\text { WY1112 analog }\end{array}$ & $\begin{array}{l}\text { CYP24A1 } \uparrow, \text { TGFB2 } \uparrow, C D 14 \uparrow, C D 97 \uparrow, \\
\text { DUSP10 }, \text { KLK6 } \uparrow\end{array}$ & $\begin{array}{l}\text { Vanoir beek } \\
\text { et al. (2009) }\end{array}$ \\
\hline
\end{tabular}

\section{Figure 6 (continued)}

http://jme.endocrinology-journals.org DOI: 10.1530/JME-11-0191
() 2013 Society for Endocrinology Printed in Great Britain
Published by Bioscientifica Ltd 


\begin{tabular}{|c|c|c|c|c|}
\hline \multirow{3}{*}{$\begin{array}{l}\text { Monocytic/ } \\
\text { promyelocytic } \\
\text { leukemia cells }\end{array}$} & $\begin{array}{l}\text { Atlas hematology filters containing } \\
406 \text { genes (Clontech Laboratories) }\end{array}$ & $\begin{array}{l}43 \text { differentially expressed genes } \\
\text { (18 upregulated and } \\
25 \text { downregulated candidates) }\end{array}$ & CD14 $\uparrow, I L 1 B \uparrow$ & $\begin{array}{l}\text { Savli et al. } \\
\text { (2002) }\end{array}$ \\
\hline & $\begin{array}{l}\text { IntelliGene HS Human Expression } \\
\text { CHIP (Takara Biomedicals, Inc., } \\
\text { Tokyo, Japan) with } 16600 \text { genes }\end{array}$ & $\begin{array}{l}583,852 \text {, and } 667 \text { genes with more } \\
\text { than a twofold intensification (many } \\
\text { correlated with differentiation-associated } \\
\text { changes toward monocyte/macrophage } \\
\text { lineages) and } 1403,655 \text {, and } 1645 \text { genes } \\
\text { with a two fold decrease after } 24,48, \\
\text { or } 72 \mathrm{~h}\end{array}$ & $\begin{array}{l}\text { CDA } \uparrow, \text { CD14 } \uparrow, \text { SERPINB1 } \uparrow, \text { NCF2 } \uparrow, \\
G 6 P D \uparrow, I L 1 B \uparrow\end{array}$ & $\begin{array}{l}\text { Suzuki et al. } \\
(2006)\end{array}$ \\
\hline & $\begin{array}{l}\text { Genome-wide ChIP-Seq mapping } \\
\text { of VDR-binding sites, Sentrix } \\
\text { Human-6 v2 Expression Bead } \\
\text { chips (Illumina, San Diego, CA, } \\
\text { USA) }\end{array}$ & $\begin{array}{l}\text { Ligand treatment revealed } 638 \text { calcitriol } \\
\text { target genes enriched in GO categories } \\
\text { associated with immunity and signaling. } \\
\text { Of } 408 \text { upregulated genes, } 72 \% \text { showed } \\
\text { VDR binding within } 400 \mathrm{~kb} \text { of their TSS; } \\
43 \% \text { of } 239 \text { downregulated candidates } \\
\text { showed VDR binding within } 400 \mathrm{~kb} \text { of } \\
\text { their TSS }\end{array}$ & $\begin{array}{l}\text { CD14 } \uparrow, \text { CD97 } \uparrow, \text { CLMN } \uparrow, \text { THBD } \uparrow, \\
\text { EFTUD1 } \uparrow, \text { PDPN } \uparrow, \text { DUSP10 } 1, \text { GOS2 } \uparrow, \\
\text { NCF2 } \uparrow, \text { P2RY2 } \uparrow, \text { TXNRD1 } \uparrow, \text { NRIP } \uparrow, \\
H B E G F \uparrow, T N F S F 10 \downarrow\end{array}$ & $\begin{array}{l}\text { Heikkinen } \\
\text { et al. (2011) }\end{array}$ \\
\hline $\begin{array}{l}\text { Ovarian cancer } \\
\text { OVCAR3 } \\
\text { cell line }\end{array}$ & $\begin{array}{l}\text { Initial Affymetrix U95Av2 vs U133A } \\
\text { (containing } 22283 \text { probe sets) } \\
\text { gene chips }\end{array}$ & $\begin{array}{l}\text { Catalog of } 58 \text { genes upregulated } \\
\text { (implemented in cell cycle, apoptosis, } \\
\text { signaling, tumor suppression, and } \\
\text { transcription); } 38 \text { genes downregulated }\end{array}$ & 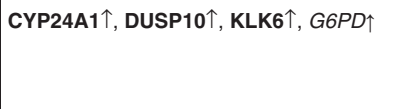 & $\begin{array}{l}\text { Zhang et al. } \\
\text { (2005) }\end{array}$ \\
\hline $\begin{array}{l}\text { Coronary artery } \\
\text { smooth } \\
\text { muscle cells }\end{array}$ & $\begin{array}{l}\text { Affymetrix U133Av2 microarray } \\
\text { with more than } 22000 \text { probe sets }\end{array}$ & $\begin{array}{l}\text { Using a cutoff value of } 2,116 \text { genes } \\
\text { were found to be significantly upregulated } \\
\text { and } 60 \text { to be downregulated. Top } \\
\text { functional DAVID clusters encompass } \\
\text { GO categories like signal transduction, } \\
\text { cell communication, growth, or } \\
\text { differentiation }\end{array}$ & $\begin{array}{l}\text { TGFB2 } \uparrow \text { within the } \\
\text { differentiation/proliferation specific GO } \\
\text { categorization }\end{array}$ & $\begin{array}{l}\text { Wu-Wong } \\
\text { et al. (2006) }\end{array}$ \\
\hline \multirow[t]{2}{*}{$\begin{array}{l}\text { Colon } \\
\text { carcinoma } \\
\text { cell line }\end{array}$} & $\begin{array}{l}\text { Affymetrix HG-U95Av2 cDNA } \\
\text { array harboring } 12625 \text { distinct } \\
\text { sequences (corresponding to } \\
\text { bout } 11300 \text { unique GenBank } \\
\text { accession numbers) }\end{array}$ & $\begin{array}{l}\text { Only } 12 \text { genes, among them two } \\
\text { previously known candidates, } \\
\text { demonstrated statistically significant } \\
\text { changes in expression of two } \\
\text { fold or greater }\end{array}$ & CYP24A1 $\uparrow$ & $\begin{array}{l}\text { Wood et al. } \\
(2004)\end{array}$ \\
\hline & $\begin{array}{l}\text { Affymetrix HG-U95A array with } \\
>12665 \text { features for individual } \\
\text { known genes and ESTs }\end{array}$ & $\begin{array}{l}81 \text { upregulated and } 20 \text { downregulated } \\
\text { genes after 4-h exposure, with only little } \\
\text { overlap to the list retrieved after } 48 \mathrm{~h} \text {. } \\
\text { Genes play roles in transcription, cell } \\
\text { adhesion, DNA synthesis, redox status, } \\
\text { translation, cytoskeleton, adhesion, } \\
\text { apoptosis, signaling, metabolism, } \\
\text { and transport }\end{array}$ & $G_{0} S 2 \uparrow$ & $\begin{array}{l}\text { Palmer et al. } \\
\text { (2003) }\end{array}$ \\
\hline \multirow[t]{2}{*}{$\begin{array}{l}\text { Primary vs } \\
\text { immortalized } \\
\text { epidermal } \\
\text { keratinocytes }\end{array}$} & $\begin{array}{l}\text { Non-redundant, small-scale set of } \\
2135 \text { pre selected, sequence- } \\
\text { verified EST clones. Two in-house- } \\
\text { spotted nylon membrane filter } \\
\text { arrays per time point }\end{array}$ & $\begin{array}{l}86 / 43 \text { positively and } 50 / 1 \text { negatively } \\
\text { regulated targets after } 12 / 24 \mathrm{~h} \text {. Genes } \\
\text { are involved in intracellular signaling, } \\
\text { cell cycle, transcription, metabolism, } \\
\text { growth, constitution of ECM, } \\
\text { cytoskeleton, apoptosis, immune } \\
\text { response, as well as DNA repair }\end{array}$ & CYP24A1 $\uparrow$, NET1 $\uparrow$, G0S2 $\uparrow$, IL1RL1 $\uparrow$. & $\begin{array}{l}\text { Moll et al. } \\
(2007)\end{array}$ \\
\hline & $\begin{array}{l}\text { Duplicate Affymetrix HG-U133A } \\
\text { GeneChips (about } 12600 \text { genes) }\end{array}$ & $\begin{array}{l}82 \text { genes were upregulated and } 16 \\
\text { were downregulated. Many candidates } \\
\text { appear implemented in immune response, } \\
\text { differentiation, and proliferation }\end{array}$ & $\begin{array}{l}\text { CD14 } \uparrow, \text { KLK6 } \uparrow, \text { KLK13 } \uparrow, \text { SERPINB1 } \uparrow, \\
\text { SEMA3B } \uparrow, \text { DUSP10 } \uparrow, \text { IL1RL1 } 1 \text { (as far } \\
\text { as accessible on the web) }\end{array}$ & $\begin{array}{l}\text { Lu et al. } \\
(2005)\end{array}$ \\
\hline $\begin{array}{l}\text { Human (pre-) } \\
\text { adipocytes }\end{array}$ & Affymetrix HG-U133A array & $\begin{array}{l}237 \text { vs } 360 \text { candidates differentially } \\
\text { responding to either calcitriol or a } \\
\text { calcitriol/cortisone combination. Targets } \\
\text { are involved in angiogenesis, cell cycle, } \\
\text { proliferation, inflammation, or oxidative } \\
\text { stress management }\end{array}$ & $\begin{array}{l}\text { CYP3A5 } \uparrow, \text { EFTUD1 } \uparrow, \text { NRIP } \uparrow, \text { SLC1A1 } \uparrow, \\
\text { SLC4A7 }, \text { PLAT } \uparrow\end{array}$ & $\begin{array}{l}\text { Sun et al. } \\
(2008)\end{array}$ \\
\hline $\begin{array}{l}\text { Lymphoblastoid } \\
\text { cell lines }\end{array}$ & $\begin{array}{l}\text { ChIP-seq defined genome-wide } \\
\text { map of VDR occupation, Affymetrix } \\
\text { GeneChip Human Exon 1.0 ST Array }\end{array}$ & $\begin{array}{l}\text { Identification of } 2776 \text { genomic positions } \\
\text { occupied by VDR (enriched near } \\
\text { autoimmune and cancer-associated } \\
\text { genes) plus } 229 \text { candidates with } \\
\text { significant changes in gene expression } \\
\text { (226 upregulated, three downregulated) }\end{array}$ & $\begin{array}{l}\text { CAB39 } \uparrow, \text { CD274 } \uparrow, \text { CD97 } \uparrow, \text { CLMN } \uparrow, \\
\text { DUSP10 } \uparrow, \text { EFTUD1 } \uparrow, \text { SERPINB1 } \uparrow, \\
\text { TMEM156 } \uparrow, \text { CYP24A1 } \uparrow\end{array}$ & $\begin{array}{l}\text { Ramagopalan } \\
\text { et al. (2010) }\end{array}$ \\
\hline
\end{tabular}

\section{Figure 6}

Medium-scale to HTP genome-wide microarray studies examining differential expression of human calcitriol targets. Individual columns depict employed cell lines, applied commercial vs in-house-established array platforms, obtained results, and evident (if any) overlap to our present work. The only two previous approaches definitely focusing on keratinocytes are highlighted in gray. Concentration and induction times typically ranged around $30-50 \mathrm{nM}$ calcitriol and $4,6,12,24,36$, 48, or $72 \mathrm{~h}$. $\uparrow$ and $\downarrow$ denote comparable fold-changes $\left(\log _{2}\right)$ or gene expression ratios as published within the respective studies. Previously reported candidate genes that were not confirmed in this study are shown in italics.

Published by Bioscientifica Ltd. 
6-h interval (Heikkinen et al. 2011) and a 24- to 72-h range (Suzuki et al. 2006) for obtaining reasonable up- or downregulation of genes that can still be considered as primary targets (Lin et al. 2002, Carlberg 2010). From our in-house-performed 3-(4,5-dimethylthiazol-2-yl)-2,5diphenyltetrazolium bromide (MTT) assay that may under applied experimental conditions - reflect the number of viable, proliferating cells by measuring the activity of cellular enzymes reducing the respective MTT dye, we can parenthetically estimate that $62.91 \%$ of primary keratinocytes are metabolically active at the $200 \mathrm{nM}$ calcitriol dose (half maximal effective concentration $\mathrm{EC}_{50}$ of $908.8 \mathrm{nM}$, Supplementary Figure 1, see section on supplementary data given at the end of this article). Consistent with both high(er)-quality single-gene approaches and with earlier microarray studies performed in diverse (tumor tissue derived) cell types, our results reveal fewer genes downregulated than upregulated (Vanoirbeek et al. 2009). Employing a RTq-PCR foldchange cutoff of 1.8 or greater, we expect our data to correlate with results from complementary test arrangements. However, several acknowledged targets, including APCDD1, G6PD, HBEGF, KLHL5, DSC1, METTL7A, IL1B, CYP4F11, TNFSF10, LYPD5, or SLC44A5, fell through our rigorous, unbiased post hoc data filtering, which distinguishes verifiable findings from false-positive fluctuations. Our RTq-PCR confirmation of 55 differentially expressed calcitriol response genes at $200 \mathrm{nM} / 16 \mathrm{~h}$, as well as the demonstration of comparable tendencies of gene regulation plus the confirmation of at least $45 \%$ of the genes as calcitriol targets using $1 \mathrm{nM}$ calcitriol for $8 \mathrm{~h}$, nonetheless affirms the potency of our streamlined experimental design while simultaneously underscoring the legitimacy of our 46 novel (among them 13 entirely new) candidates. Because we measured changes in gene expression at only one concentration of calcitriol at a single time point for microarray analysis and reevaluated only 78 of the 86 original candidates derived from the whole-transcriptome microarray chip at two concentrations, our confirmed list of regulated genes likely reflects an underestimate of the total number of calcitriol targets in primary keratinocytes.

Lastly, our RTq-PCR-evaluated data have been complemented by literature-inspired (Wang et al. 2005, Carlberg \& Heinäniemi 2010), weighted nucleotide distribution matrix-based predictions that assign (near) consensus nuclear hormone receptor superfamily response elements (Cartharius et al. 2005). As the affinity of a monomeric VDR molecule to a single-core binding motif is not sufficient to allow optimal DNA binding, transcriptional control of primary calcitriol targets is preferentially achieved by association of VDR-RXR heterodimers to the major groove of classical DR3-type (i.e. spaced by three intervening nucleotides) repeats of the hexamer sequence RGKTSA (where R is A or G, $\mathrm{K}$ is $\mathrm{G}$ or T, and S is C or G) (Shaffer \& Gewirth 2002, Carlberg et al. 2007). Furthermore, effective linkage has also been observed on DR6, DR5, and DR4 VDREs as well as on cisacting everted repeat structures with seven to nine intervening nucleotides, arrangements that are not decidedly included in the exploited prediction profile (Toell et al. 2000). Using weighted nucleotide distribution matrix-based in silico predictions, we have been able to uncover putative direct VDR-binding sites within the promoter regions of 50 (90.9\%) of our RTq-PCR-confirmed candidates. Of the 13 entirely new calcitriol target genes identified by our study, 11 reveal variable numbers plus combinations of response elements, with (bipartite) DR3s actually prevailing. Definite recombinant VDR-DBD binding to (bipartite) DR3 repeats could be confirmed for three out of five randomly selected candidates genes and thereby provides us with both a level of further validation and a putative mechanism of regulation. Nevertheless, definite VDRE uncovering does not signify unambiguous response element functioning in vivo, as VDRE may be covered by nucleosomes (especially elements in locations isolated from transcription factor 'modules'), while maintenance of responsiveness may, on the other hand, not demand strict binding site conservation (Toell et al. 2000, Carlberg \& Seuter 2009).

In conclusion, our study suggests that the role of calcitriol in human primary keratinocytes is more complex than perhaps formerly anticipated. It also illuminates how continuing, sophisticated endeavors can significantly contribute to a further description of novel calcitriol targets - information that is indispensable for our enhanced understanding of underlying (regulatory) pathways and associated disease phenotypes at the molecular level. We nevertheless have to acknowledge some apparent restrictions of this study, namely its absolute in vitro nature and its probably limited representativeness of biological data. A better, physiologically more relevant, complementation for future corroboration of this first overall impression on novel calcitriol response genes could be to isolate keratinocytes from patients treated with different calcitriol doses and align with existing in vitro data. Although whole-transcriptome microarrays were admittedly performed with RNA isolated from only one single individual, the majority of differentially regulated calcitriol target genes could nonetheless be confirmed in a complementary RTq-PCR setup

Published by Bioscientifica Ltd. 
averaged over three/six individuals. Because calculated interindividual variation has been determined to lie in the $10 \%$ range, our combined data represent a consistent compromise - even if several literature-described targets fell through our rigorous data filtering. Also, the specific physiological engagement of proposed candidates in calcitriol-mediated cellular activities remains to be appraised in the follow-up assays, such as RNA interference/knockdown approaches or yeast two-hybrid (Y2H) systems that could depict elementary reaction partner networks. In the long run, the 'hit list' presented here, compiled with (eventually re-validated) small-scale to HTP experimental results, could guide the prioritization of new therapeutic targets. As well, this list could serve as a test system for revealing distinct molecular actions (e.g. with respect to differences in gene expression or in induction levels) of synthetic vitamin D analogs synthesized with the goal of improving the biological (calcemic) profile of the natural substance for therapeutic applications, as for example, in hyperproliferative skin pathologies such as psoriasis or various cancer types (Holick 2003).

\section{Supplementary data}

This is linked to the online version of the paper at http://dx.doi.org/10.1530/ JME-11-0191.

\section{Declaration of interest}

The authors declare that there is no conflict of interest that could be perceived as prejudicing the impartiality of the research reported.

\section{Funding}

This research did not receive any specific grant from any funding agency in the public, commercial or not-for-profit sector.

\section{References}

Akutsu N, Lin R, Bastien Y, Bestawros A, Enepekides DJ, Black MJ \& White JH 2001 Regulation of gene expression by 1 $\alpha$,25-dihydroxyvitamin $\mathrm{D}_{3}$ and its analog EB1089 under growth-inhibitory conditions in squamous carcinoma cells. Molecular Endocrinology 15 1127-1139. (doi:10.1210/me.15.7.1127)

Anderson PH, O'Loughlin PD, May BK \& Morris HA 2003 Quantification of mRNA for the vitamin D metabolizing enzymes CYP27B1 and CYP24 and vitamin D receptor in kidney using real-time reverse transcriptasepolymerase chain reaction. Journal of Molecular Endocrinology $\mathbf{3 1}$ 123-132. (doi:10.1677/jme.0.0310123)

Ashburner M, Ball CA, Blake JA, Botstein D, Butler H, Cherry JM, Davis AP, Dolinski K, Dwight SS, Eppig JT et al. 2000 Gene ontology: tool for the unification of biology. The Gene Ontology Consortium. Nature Genetics 25 25-29. (doi:10.1038/75556)

Auer H, Newsom DL \& Kornacker K 2009 Expression Profiling Using Affymetrix GeneChip Microarrays. Methods in Molecular Biology 509 35-46. (doi:10.1007/978-1-59745-372-1_3)
Bikle DD 2010 Vitamin D and the skin. Journal of Bone and Mineral Metabolism 28 117-130. (doi:10.1007/s00774-009-0153-8)

Bikle DD, Nemanic MK, Whitney JO \& Elias PW 1986 Neonatal human foreskin keratinocytes produce 1,25-dihydroxyvitamin $\mathrm{D}_{3}$. Biochemistry 25 1545-1548. (doi:10.1021/bi00355a013)

Bikle DD, Ng D, Oda Y, Hanley K, Feingold K \& Xie Z 2002 The vitamin D response element of the involucrin gene mediates its regulation by 1,25-dihydroxyvitamin $\mathrm{D}_{3}$. Journal of Investigative Dermatology 119 1109-1113. (doi:10.1046/j.1523-1747.2002.19508.x)

Bikle D, Teichert A, Hawker N, Xie Z \& Oda Y 2007 Sequential regulation of keratinocyte differentiation by $1,25(\mathrm{OH})_{2} \mathrm{D}_{3}, \mathrm{VDR}$, and its coregulators. Journal of Steroid Biochemistry and Molecular Biology 103 396-404. (doi:10.1016/j.jsbmb.2006.12.063)

Boyan BD, Wang L, Wong KL, Jo H \& Schwartz Z 2006 Plasma membrane requirements for $1 \alpha, 25(\mathrm{OH})_{2} \mathrm{D}_{3}$ dependent PKC signaling in chondrocytes and osteoblasts. Steroids 71 286-290. (doi:10.1016/j.steroids. 2005.09.018)

Carlberg C 2003 Current understanding of the function of the nuclear vitamin D receptor in response to its natural and synthetic ligands. Recent Results in Cancer Research 164 29-42.

Carlberg C 2004 Ligand-mediated conformational changes of the VDR are required for gene transactivation. Journal of Steroid Biochemistry and Molecular Biology 89-90 227-232. (doi:10.1016/j. jsbmb.2004.03.112)

Carlberg C 2010 Diversity of vitamin D target genes. In Nutrition and Health: Vitamin D. pp 255-274. Ed MF Holick. Humana Press.

Carlberg C \& Heinäniemi M 2010 The impact of whole genome in silico screening for nuclear receptor-binding sites in systems biology. In Elements of Computational Systems Biology. Eds H Lodhi \& S Muggleton. John Wiley \& Sons, Inc.

Carlberg C \& Seuter S 2007 The vitamin D receptor. Dermatologic Clinics 25 515-523, viii. (doi:10.1016/j.det.2007.06.004)

Carlberg C \& Seuter S 2009 A genomic perspective on vitamin D signaling. Anticancer Research 29 3485-3493. (doi:10.1002/9780470556757.ch13)

Carlberg C, Dunlop TW, Saramaki A, Sinkkonen L, Matilainen M \& Vaisanen S 2007 Controlling the chromatin organization of vitamin D target genes by multiple vitamin D receptor binding sites. Journal of Steroid Biochemistry and Molecular Biology 103 338-343. (doi:10.1016/ j.jsbmb.2006.12.044)

Cartharius K, Frech K, Grote K, Klocke B, Haltmeier M, Klingenhoff A, Frisch M, Bayerlein M \& Werner T 2005 MatInspector and beyond: promoter analysis based on transcription factor binding sites. Bioinformatics 21 2933-2942. (doi:10.1093/bioinformatics/bti473)

Cianferotti L, Cox M, Skorija K \& Demay MB 2007 Vitamin D receptor is essential for normal keratinocyte stem cell function. PNAS $\mathbf{1 0 4}$ 9428-9433. (doi:10.1073/pnas.0702884104)

Dallas PB, Gottardo NG, Firth MJ, Beesley AH, Hoffmann K, Terry PA, Freitas JR, Boag JM, Cummings AJ \& Kees UR 2005 Gene expression levels assessed by oligonucleotide microarray analysis and quantitative real-time RT-PCR - how well do they correlate? BMC Genomics 659. (doi:10.1186/1471-2164-6-59)

Dalma-Weiszhausz DD, Warrington J, Tanimoto EY \& Miyada CG 2006 The affymetrix GeneChip platform: an overview. Methods in Enzymology 410 3-28.

Darimont BD, Wagner RL, Apriletti JW, Stallcup MR, Kushner PJ, Baxter JD, Fletterick RJ \& Yamamoto KR 1998 Structure and specificity of nuclear receptor-coactivator interactions. Genes and Development 12 3343-3356. (doi:10.1101/gad.12.21.3343)

Diker-Cohen T, Koren R, Liberman UA \& Ravid A 2003 Vitamin D protects keratinocytes from apoptosis induced by osmotic shock, oxidative stress, and tumor necrosis factor. Annals of the New York Academy of Sciences 1010 350-353. (doi:10.1196/annals.1299.064)

Ebert R, Schutze N, Adamski J \& Jakob F 2006 Vitamin D signaling is modulated on multiple levels in health and disease. Molecular and Cellular Endocrinology 248 149-159. (doi:10.1016/j.mce.2005.11.039)

Published by Bioscientifica Ltd. 
Eelen G, Verlinden L, De Clercq P, Vandewalle M, Bouillon R \& Verstuyf A 2006 Vitamin D analogs and coactivators. Anticancer Research 26 $2717-2721$.

Farach-Carson MC \& Xu Y 2002 Microarray detection of gene expression changes induced by $1,25(\mathrm{OH})(2) \mathrm{D}(3)$ and a $\mathrm{Ca}(2+)$ influx-activating analog in osteoblastic ROS 17/2.8 cells. Steroids 67 467-470. (doi:10.1016/S0039-128X(01)00168-4)

Heikkinen S, Vaisanen S, Pehkonen P, Seuter S, Benes V \& Carlberg C 2011 Nuclear hormone $1 \alpha, 25$-dihydroxyvitamin $\mathrm{D}_{3}$ elicits a genome-wide shift in the locations of VDR chromatin occupancy. Nucleic Acids Research.

Hermanson O, Glass CK \& Rosenfeld MG 2002 Nuclear receptor coregulators: multiple modes of modification. Trends in Endocrinology and Metabolism 13 55-60. (doi:10.1016/S1043-2760(01)00527-6)

Hijiya N, Setoguchi M, Matsuura K, Higuchi Y, Akizuki S \& Yamamoto S 1994 Cloning and characterization of the human osteopontin gene and its promoter. Biochemical Journal 303 255-262.

Holick MF 2003 Vitamin D: a millenium perspective. Journal of Cellular Biochemistry 88 296-307. (doi:10.1002/jcb.10338)

Hosack DA, Dennis G Jr, Sherman BT, Lane HC \& Lempicki RA 2003 Identifying biological themes within lists of genes with EASE. Genome Biology 4 R70. (doi:10.1186/gb-2003-4-10-r70)

Huang da W, Sherman BT \& Lempicki RA 2009 Systematic and integrative analysis of large gene lists using DAVID bioinformatics resources. Nature Protocols 4 44-57. (doi:10.1038/nprot.2008.211)

Kawasaki ES 2006 The end of the microarray Tower of Babel: will universal standards lead the way? Journal of Biomolecular Techniques 17 200-206.

Khanim FL, Gommersall LM, Wood VH, Smith KL, Montalvo L, O'Neill LP, Xu Y, Peehl DM, Stewart PM, Turner BM et al. 2004 Altered SMRT levels disrupt vitamin $\mathrm{D}_{3}$ receptor signalling in prostate cancer cells. Oncogene 23 6712-6725. (doi:10.1038/sj.onc.1207772)

Kovalenko PL, Zhang Z, Cui M, Clinton SK \& Fleet JC 2010 1,25 Dihydroxyvitamin D-mediated orchestration of anticancer, transcriptlevel effects in the immortalized, non-transformed prostate epithelial cell line, RWPE1. BMC Genomics 11 26. (doi:10.1186/1471-2164-11-26)

Kriebitzsch C, Verlinden L, Eelen G, Tan BK, Van Camp M, Bouillon R \& Verstuyf A 2009 The impact of $1,25(\mathrm{OH})_{2} \mathrm{D}_{3}$ and its structural analogs on gene expression in cancer cells - a microarray approach. Anticancer Research 29 3471-3483.

Krishnan AV, Shinghal R, Raghavachari N, Brooks JD, Peehl DM \& Feldman D 2004 Analysis of vitamin D-regulated gene expression in LNCaP human prostate cancer cells using cDNA microarrays. Prostate 59 243-251. (doi:10.1002/pros.20006)

Lee J \& Youn JI 1998 The photoprotective effect of 1,25-dihydroxyvitamin $\mathrm{D}_{3}$ on ultraviolet light B-induced damage in keratinocyte and its mechanism of action. Journal of Dermatological Science 18 11-18. (doi:10.1016/S0923-1811(98)00015-2)

Lehmann B, Genehr T, Knuschke P, Pietzsch J \& Meurer M 2001 UVBinduced conversion of 7-dehydrocholesterol to 1 1,25-dihydroxyvitamin $\mathrm{D}_{3}$ in an in vitro human skin equivalent model. Journal of Investigative Dermatology 117 1179-1185. (doi:10.1046/j.0022-202x. 2001.01538.x)

Lehmann B, Sauter W, Knuschke P, Dressler S \& Meurer M 2003 Demonstration of UVB-induced synthesis of $1 \alpha, 25$-dihydroxyvitamin $\mathrm{D}_{3}$ (calcitriol) in human skin by microdialysis. Archives of Dermatological Research 295 24-28.

Lemon BD \& Freedman LP 1996 Selective effects of ligands on vitamin $\mathrm{D}_{3}$ receptor- and retinoid $\mathrm{X}$ receptor-mediated gene activation in vivo. Molecular and Cellular Biology 16 1006-1016.

Lin R, Nagai Y, Sladek R, Bastien Y, Ho J, Petrecca K, Sotiropoulou G, Diamandis EP, Hudson TJ \& White JH 2002 Expression profiling in squamous carcinoma cells reveals pleiotropic effects of vitamin $\mathrm{D}_{3}$ analog EB1089 signaling on cell proliferation, differentiation, and immune system regulation. Molecular Endocrinology 16 1243-1256. (doi:10.1210/me.16.6.1243)
Losel R \& Wehling M 2003 Nongenomic actions of steroid hormones. Nature Reviews. Molecular Cell Biology 4 46-56. (doi:10.1038/nrm1009)

Lu J, Goldstein KM, Chen P, Huang S, Gelbert LM \& Nagpal S 2005 Transcriptional profiling of keratinocytes reveals a vitamin D-regulated epidermal differentiation network. Journal of Investigative Dermatology 124 778-785. (doi:10.1111/j.0022-202X.2005.23641.x)

Lutzow-Holm C, Heyden A, Huitfeldt HS, Brandtzaeg P \& Clausen OP 1995 Topical application of calcitriol alters expression of filaggrin but not keratin K1 in mouse epidermis. Archives of Dermatological Research $\mathbf{2 8 7}$ 480-487. (doi:10.1007/BF00373432)

McLane JA, Katz M \& Abdelkader N 1990 Effect of 1,25-dihydroxyvitamin $\mathrm{D}_{3}$ on human keratinocytes grown under different culture conditions. In Vitro Cellular \& Developmental Biology 26 379-387. (doi:10.1007/ BF02623829)

Meyer MB, Goetsch PD \& Pike JW 2010 Genome-wide analysis of the VDR/RXR cistrome in osteoblast cells provides new mechanistic insight into the actions of the vitamin D hormone. Journal of Steroid Biochemistry and Molecular Biology 121 136-141. (doi:10.1016/j.jsbmb. 2010.02.011)

Moll PR, Sander V, Frischauf AM \& Richter K 2007 Expression profiling of vitamin D treated primary human keratinocytes. Journal of Cellular Biochemistry 100 574-592. (doi:10.1002/jcb.21061)

Norman AW 2006 Minireview: vitamin D receptor: new assignments for an already busy receptor. Endocrinology 147 5542-5548. (doi:10.1210/ en.2006-0946)

Oda Y, Uchida Y, Moradian S, Crumrine D, Elias PM \& Bikle DD 2009 Vitamin D receptor and coactivators SRC2 and 3 regulate epidermisspecific sphingolipid production and permeability barrier formation. Journal of Investigative Dermatology 129 1367-1378. (doi:10.1038/ jid.2008.380)

Oender K, Trost A, Lanschuetzer C, Laimer M, Emberger M, Breitenbach M, Richter K, Hintner H \& Bauer JW 2008 Cytokeratin-related loss of cellular integrity is not a major driving force of human intrinsic skin aging. Mechanisms of Ageing and Development 129 563-571. (doi:10.1016/j.mad.2008.05.008)

Palmer HG, Sanchez-Carbayo M, Ordonez-Moran P, Larriba MJ, Cordon-Cardo C \& Munoz A 2003 Genetic signatures of differentiation induced by 1 $\alpha, 25$-dihydroxyvitamin $\mathrm{D}_{3}$ in human colon cancer cells. Cancer Research 63 7799-7806.

Peehl DM, Shinghal R, Nonn L, Seto E, Krishnan AV, Brooks JD \& Feldman D 2004 Molecular activity of 1,25-dihydroxyvitamin $\mathrm{D}_{3}$ in primary cultures of human prostatic epithelial cells revealed by cDNA microarray analysis. Journal of Steroid Biochemistry and Molecular Biology 92 131-141. (doi:10.1016/j.jsbmb.2004.07.003)

Pfaffl MW 2001 A new mathematical model for relative quantification in real-time RT-PCR. Nucleic Acids Research 29 e45. (doi:10.1093/nar/ 29.9.e45)

Pike JW, Meyer MB, Martowicz ML, Bishop KA, Lee SM, Nerenz RD \& Goetsch PD 2010 Emerging regulatory paradigms for control of gene expression by 1,25-dihydroxyvitamin $\mathrm{D}_{3}$. Journal of Steroid Biochemistry and Molecular Biology 121 130-135. (doi:10.1016/j.jsbmb.2010.02.036)

Polly P, Herdick M, Moehren U, Baniahmad A, Heinzel T \& Carlberg C 2000 VDR-Alien: a novel, DNA-selective vitamin D(3) receptor-corepressor partnership. FASEB Journal 14 1455-1463. (doi:10.1096/fj.14.10.1455)

Poumay Y \& Coquette A 2007 Modelling the human epidermis in vitro: tools for basic and applied research. Archives of Dermatological Research 298 361-369. (doi:10.1007/s00403-006-0709-6)

Privalsky ML 2004 The role of corepressors in transcriptional regulation by nuclear hormone receptors. Annual Review of Physiology 66 315-360. (doi:10.1146/annurev.physiol.66.032802.155556)

Provenzano M \& Mocellin S 2007 Complementary techniques: validation of gene expression data by quantitative real time PCR. Advances in Experimental Medicine and Biology 593 66-73.

Ramagopalan SV, Heger A, Berlanga AJ, Maugeri NJ, Lincoln MR, Burrell A, Handunnetthi L, Handel AE, Disanto G, Orton SM et al. 2010 A ChIP-seq defined genome-wide map of vitamin D receptor binding: 
associations with disease and evolution. Genome Research 20 1352-1360. (doi:10.1101/gr.107920.110)

Rastinejad F, Perlmann T, Evans RM \& Sigler PB 1995 Structural determinants of nuclear receptor assembly on DNA direct repeats. Nature 375 203-211. (doi:10.1038/375203a0)

Reichrath J, Lehmann B, Carlberg C, Varani J \& Zouboulis CC 2007 Vitamins as hormones. Hormone and Metabolic Research 39 71-84. (doi:10.1055/s-2007-958715)

Rosenfeld MG \& Glass CK 2001 Coregulator codes of transcriptional regulation by nuclear receptors. Journal of Biological Chemistry 276 36865-36868. (doi:10.1074/jbc.R100041200)

Sarmah CK \& Samarasinghe S 2011 Microarray gene expression: a study of between-platform association of Affymetrix and cDNA arrays. Computational Biology and Medicine 41 980-986. (doi:10.1016/j.compbiomed. 2011.08.007)

Savli H, Aalto Y, Nagy B, Knuutila S \& Pakkala S 2002 Gene expression analysis of $1,25(\mathrm{OH})_{2} \mathrm{D}_{3}$-dependent differentiation of HL-60 cells: a cDNA array study. British Journal of Haematology 118 1065-1070. (doi:10.1046/j.1365-2141.2002.03734.x)

Schauber J, Dorschner RA, Coda AB, Buchau AS, Liu PT, Kiken D, Helfrich YR, Kang S, Elalieh HZ, Steinmeyer A et al. 2007 Injury enhances TLR2 function and antimicrobial peptide expression through a vitamin D-dependent mechanism. Journal of Clinical Investigation 117 803-811. (doi:10.1172/JCI30142)

Schmuth M, Watson RE, Deplewski D, Dubrac S, Zouboulis CC \& Griffiths CE 2007 Nuclear hormone receptors in human skin. Hormone and Metabolic Research 39 96-105. (doi:10.1055/s-2007-961808)

Shaffer PL \& Gewirth DT 2002 Structural basis of VDR-DNA interactions on direct repeat response elements. EMBO Journal 21 2242-2252. (doi:10.1093/emboj/21.9.2242)

Sherman BT, Huang da W, Tan Q, Guo Y, Bour S, Liu D, Stephens R, Baseler MW, Lane HC \& Lempicki RA 2007 DAVID Knowledgebase: a gene-centered database integrating heterogeneous gene annotation resources to facilitate high-throughput gene functional analysis. BMC Bioinformatics 8 426. (doi:10.1186/1471-2105-8-426)

Shi L, Reid LH, Jones WD, Shippy R, Warrington JA, Baker SC, Collins PJ, de Longueville F, Kawasaki ES, Lee KY et al. 2006 The MicroArray Quality Control (MAQC) project shows inter- and intraplatform reproducibility of gene expression measurements. Nature Biotechnology 24 1151-1161. (doi:10.1038/nbt1239)

Sone T, Kerner S \& Pike JW 1991 Vitamin D receptor interaction with specific DNA. Association as a 1,25-dihydroxyvitamin $\mathrm{D}_{3}$-modulated heterodimer. Journal of Biological Chemistry 266 23296-23305.

Su MJ, Bikle DD, Mancianti ML \& Pillai S 1994 1,25-Dihydroxyvitamin $\mathrm{D}_{3}$ potentiates the keratinocyte response to calcium. Journal of Biological Chemistry 269 14723-14729.

Sun X, Morris KL \& Zemel MB 2008 Role of calcitriol and cortisol on human adipocyte proliferation and oxidative and inflammatory stress: a microarray study. Journal of Nutrigenetics and Nutrigenomics 1 30-48. (doi:10.1159/000109873)

Suzuki T, Tazoe H, Taguchi K, Koyama Y, Ichikawa H, Hayakawa S, Munakata H \& Isemura M 2006 DNA microarray analysis of changes in gene expression induced by 1,25-dihydroxyvitamin $\mathrm{D}_{3}$ in human promyelocytic leukemia HL-60 cells. Biomedical Research 27 99-109. (doi:10.2220/biomedres.27.99)

Svendsen ML, Daneels G, Geysen J, Binderup L \& Kragballe K 1997 Proliferation and differentiation of cultured human keratinocytes is modulated by $1,25(\mathrm{OH})_{2} \mathrm{D}_{3}$ and synthetic vitamin $\mathrm{D}_{3}$ analogues in a cell density-, calcium- and serum-dependent manner. Pharmacology \& Toxicology 80 49-56. (doi:10.1111/j.1600-0773.1997.tb00283.x)

Swami S, Raghavachari N, Muller UR, Bao YP \& Feldman D 2003 Vitamin D growth inhibition of breast cancer cells: gene expression patterns assessed by cDNA microarray. Breast Cancer Research and Treatment $\mathbf{8 0}$ 49-62. (doi:10.1023/A:1024487118457)

Tavera-Mendoza LE, Mader S \& White JH 2006 Genome-wide approaches for identification of nuclear receptor target genes. Nuclear Receptor Signaling 4 e018.

Toell A, Polly P \& Carlberg C 2000 All natural DR3-type vitamin D response elements show a similar functionality in vitro. Biochemical Journal $\mathbf{3 5 2}$ 301-309. (doi:10.1042/0264-6021:3520301)

Trost A, Desch P, Wally V, Haim M, Maier RH, Reitsamer HA, Hintner H, Bauer JW \& Onder K 2010 Aberrant heterodimerization of keratin 16 with keratin 6A in HaCaT keratinocytes results in diminished cellular migration. Mechanisms of Ageing and Development 131 346-353. (doi:10.1016/j.mad.2010.04.002)

Vanoirbeek E, Eelen G, Verlinden L, Marchal K, Engelen K, De Moor B, Beullens I, Marcelis S, De Clercq P, Bouillon R et al. 2009 Microarray analysis of MCF-7 breast cancer cells treated with 1,25-dihydroxyvitamin $\mathrm{D}_{3}$ or a 17-methyl-D-ring analog. Anticancer Research 29 3585-3590.

Wali RK, Baum CL, Sitrin MD \& Brasitus TA 1990 1,25(OH) $)_{2}$ vitamin $\mathrm{D}_{3}$ stimulates membrane phosphoinositide turnover, activates protein kinase $\mathrm{C}$, and increases cytosolic calcium in rat colonic epithelium. Journal of Clinical Investigation 85 1296-1303. (doi:10.1172/JCI114567)

Walker NJ 2001 Real-time and quantitative PCR: applications to mechanism-based toxicology. Journal of Biochemical and Molecular Toxicology 15 121-127. (doi:10.1002/jbt.8)

Wang TT, Nestel FP, Bourdeau V, Nagai Y, Wang Q, Liao J, Tavera-Mendoza L, Lin R, Hanrahan JW, Mader S et al. 2004 Cutting edge: 1,25-dihydroxyvitamin $\mathrm{D}_{3}$ is a direct inducer of antimicrobial peptide gene expression. Journal of Immunology 173 2909-2912.

Wang TT, Tavera-Mendoza LE, Laperriere D, Libby E, MacLeod NB, Nagai Y, Bourdeau V, Konstorum A, Lallemant B, Zhang R et al. 2005 Large-scale in silico and microarray-based identification of direct 1,25-dihydroxyvitamin $\mathrm{D}_{3}$ target genes. Molecular Endocrinology 19 2685-2695. (doi:10. 1210/me.2005-0106)

Wang WL, Chatterjee N, Chittur SV, Welsh J \& Tenniswood MP 2011 Effects of $1 \alpha, 25$ dihydroxyvitamin $\mathrm{D}_{3}$ and testosterone on miRNA and mRNA expression in LNCaP cells. Molecular Cancer 10 58. (doi:10.1186/ 1476-4598-10-58)

White JH 2004 Profiling 1,25-dihydroxyvitamin $\mathrm{D}_{3}$-regulated gene expression by microarray analysis. Journal of Steroid Biochemistry and Molecular Biology 89-90 239-244. (doi:10.1016/j.jsbmb.2004.03.074)

Wood RJ, Tchack L, Angelo G, Pratt RE \& Sonna LA 2004 DNA microarray analysis of vitamin D-induced gene expression in a human colon carcinoma cell line. Physiological Genomics 17 122-129. (doi:10.1152/ physiolgenomics.00002.2003)

Wu-Wong JR, Nakane M \& Ma J 2006 Effects of vitamin D analogs on the expression of plasminogen activator inhibitor-1 in human vascular cells. Thrombosis Research 118 709-714. (doi:10.1016/j.thromres.2005. 10.017)

Xie Z, Komuves L, Yu QC, Elalieh H, Ng DC, Leary C, Chang S, Crumrine D, Yoshizawa T, Kato S et al. 2002 Lack of the vitamin D receptor is associated with reduced epidermal differentiation and hair follicle growth. Journal of Investigative Dermatology 118 11-16. (doi:10.1046/ j.1523-1747.2002.01644.x)

Xuan Z, Zhao F, Wang J, Chen G \& Zhang MQ 2005 Genome-wide promoter extraction and analysis in human, mouse, and rat. Genome Biology 6 R72. (doi:10.1186/gb-2005-6-8-r72)

Zhang X, Li P, Bao J, Nicosia SV, Wang H, Enkemann SA \& Bai W 2005 Suppression of death receptor-mediated apoptosis by 1,25-dihydroxyvitamin $\mathrm{D}_{3}$ revealed by microarray analysis. Journal of Biological Chemistry 280 35458-35468. (doi:10.1074/jbc.M506648200)

Received in final form 4 December 2012

Accepted 18 December 2012

Accepted Preprint published online 18 December 2012 http://jme.endocrinology-journals.org DOI: 10.1530/JME-11-0191
() 2013 Society for Endocrinology Printed in Great Britain 